\title{
Toll-like receptor 4-mediated lymphocyte influx induces neonatal necrotizing enterocolitis
}

\author{
Charlotte E. Egan, ${ }^{1,2}$ Chhinder P. Sodhi, ${ }^{3,4}$ Misty Good, ${ }^{5}$ Joyce Lin, ${ }^{1,6}$ Hongpeng Jia, ${ }^{3,4}$ Yukihiro Yamaguchi, ${ }^{3,4}$ Peng Lu, ${ }^{3,4}$ \\ Congrong Ma,, Maria F. Branca, ,,2 Samantha Weyandt, ${ }^{1,2}$ William B. Fulton,, ${ }^{3,4}$ Diego F. Niño,, ${ }^{3,4}$ Thomas Prindle Jr., ${ }^{3,4}$ \\ John A. Ozolek, ${ }^{6}$ and David J. Hackam ${ }^{3,4}$ \\ 'Division of Pediatric Surgery, Children's Hospital of Pittsburgh, Pittsburgh, Pennsylvania, USA. ²Department of Surgery, University of Pittsburgh School of Medicine, Pittsburgh, Pennsylvania, USA. \\ ${ }^{3}$ General Pediatric Surgery, Johns Hopkins University and Bloomberg Children's Center, Johns Hopkins Hospital, Baltimore, Maryland, USA. ${ }^{4}$ Department of Surgery, Johns Hopkins University, \\ Baltimore, Maryland, USA. ${ }^{5}$ Division of Newborn Medicine and ${ }^{6}$ Division of Pediatric Pathology, Children's Hospital of Pittsburgh, Pittsburgh, Pennsylvania, USA.
}

\begin{abstract}
The nature and role of the intestinal leukocytes in necrotizing enterocolitis (NEC), a severe disease affecting premature infants, remain unknown. We now show that the intestine in mouse and human NEC is rich in lymphocytes that are required for NEC development, as recombination activating gene 1-deficient (Rag 1/-) $^{-1}$ mice were protected from NEC and transfer of intestinal lymphocytes from NEC mice into naive mice induced intestinal inflammation. The intestinal expression of the lipopolysaccharide receptor TLR4, which is higher in the premature compared with full-term human and mouse intestine, is required for lymphocyte influx through TLR4-mediated upregulation of CCR9/CCL25 signaling. TLR4 also mediates a STAT3-dependent polarization toward increased proinflammatory $\mathrm{CD}^{+} \mathrm{CD}^{+} \mathrm{IL}-17^{+}$and reduced tolerogenic Foxp3+ Treg lymphocytes (Tregs). Th17 lymphocytes were required for NEC development, as inhibition of STAT3 or IL-17 receptor signaling attenuated NEC in mice, while IL-17 release impaired enterocyte tight junctions, increased enterocyte apoptosis, and reduced enterocyte proliferation, leading to NEC. Importantly, TLR4-dependent Th17 polarization could be reversed by the enteral administration of retinoic acid, which induced Tregs and decreased NEC severity. These findings identify an important role for proinflammatory lymphocytes in NEC development via intestinal epithelial TLR4 that could be reversed through dietary modification.
\end{abstract}

\section{Introduction}

Necrotizing enterocolitis (NEC) is a severe inflammatory disease that affects the gastrointestinal tract of the premature infant and that causes significant morbidity and mortality in this vulnerable population (1). Despite several decades of research into the pathogenesis of NEC (2), the pathophysiological underpinnings of this disease remain incompletely understood (3) and novel therapeutic approaches remain elusive (4). The pathologic features of NEC include the accumulation of a rich inflammatory cell infiltrate into the intestinal mucosa of the premature host and the development of systemic sepsis, which together reflect a marked disruption of the intestinal barrier (5). In seeking to understand the pathogenesis of NEC, we and others have focused on the observation that the interaction between host microbes and the intestinal epithelium plays a driving role in this disease. Specifically, activation of the receptor for bacterial endotoxin, namely TLR4, which is expressed at significantly higher levels on the intestinal epithelium of the premature mouse and human gut, is required for the development of NEC (6-15). Accordingly, strategies that inhibit TLR4 signaling - including small molecules (16), amniotic fluid (17), breast milk (10), and genetic deletion of TLR4 from the intestinal epithelium (6) - attenuate NEC severity in animal models. However, these and other studies have largely focused

Conflict of interest: The authors have declared that no conflict of interest exists. Submitted: June 18, 2015; Accepted: November 13, 2015.

Reference information: / Clin Invest. 2016;126(2):495-508. doi:10.1172/JCI83356. on the intestinal epithelium itself as playing the dominant role in the development of NEC $(3,18)$ without significant focus on the nature and effects of the infiltrating inflammatory cells that interact with the intestinal epithelium, despite the important potential role for inflammatory cells in mediating this disease. Moreover, the existence of a link - if there is one - between the elevated TLR4 expression that characterizes the premature gut and the inflammatory cellular infiltrate that is observed in the intestine in NEC remains largely unexplored.

We now hypothesize that the inflammatory cells found in the intestinal mucosa of patients and mice with NEC $(19,20)$ are actually primary instigators of this disease process and are regulated by TLR4 on the intestinal epithelium (21). In support of this hypothesis, we now show that NEC is a lymphocyte-mediated disease that is regulated by intestinal epithelial TLR4 activation, which elicits a lymphocytic infiltrate via induction of CCL25 expression within the intestinal epithelium. Subsequently, persistent TLR4 signaling was found to alter the balance of regulatory (Treg) versus inflammatory (Th17) populations of $\mathrm{CD}^{+} \mathrm{T}$ cells within the newborn gut by specifically skewing the tolerogenic $\mathrm{CD} 4^{+}$Tregs toward an injurious Th17 population in a STAT3-dependent manner, leading to the severe gut inflammation that characterizes NEC. We further demonstrate that dietary strategies that can restore lymphocyte homeostasis toward Tregs, including the administration of all transretinoic acid and inhibitors of STAT3 signaling, can profoundly reduce NEC severity in animal models, suggesting therapeutic approaches for this devastating disease. 
Mouse
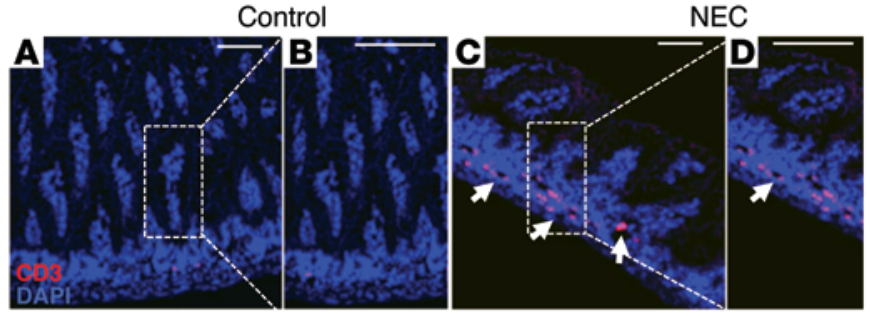

I

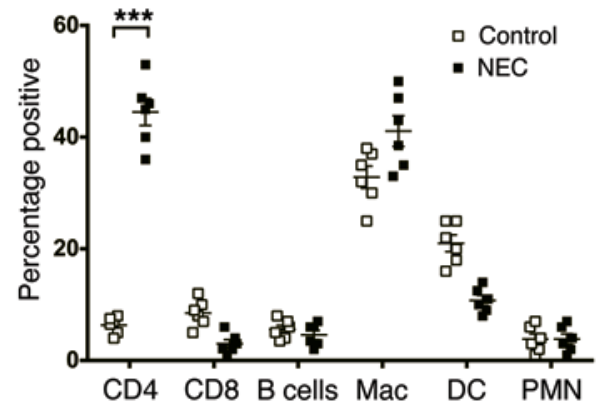

M

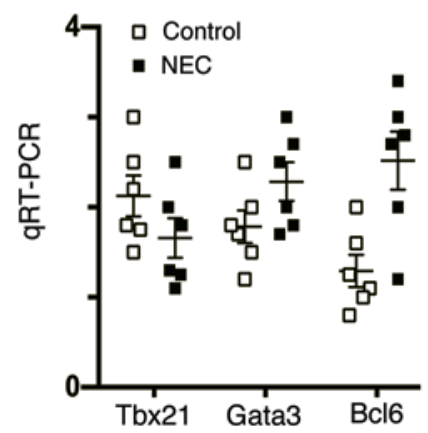

J

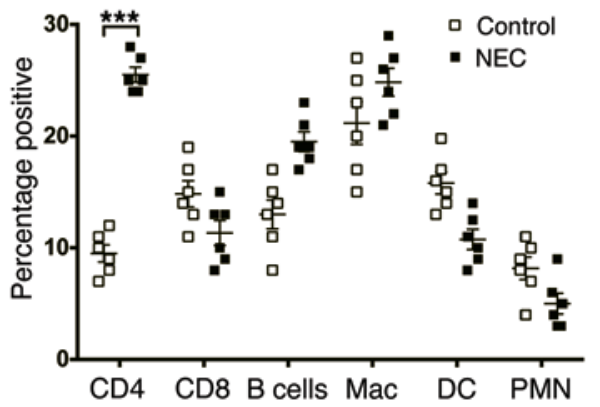

Human
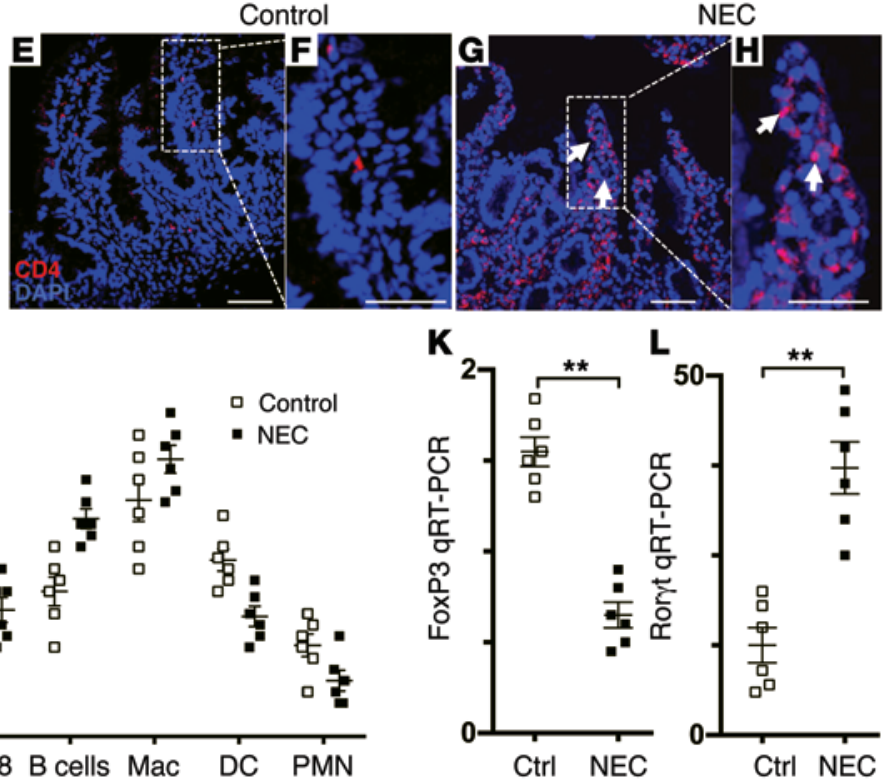

$\mathbf{R}$
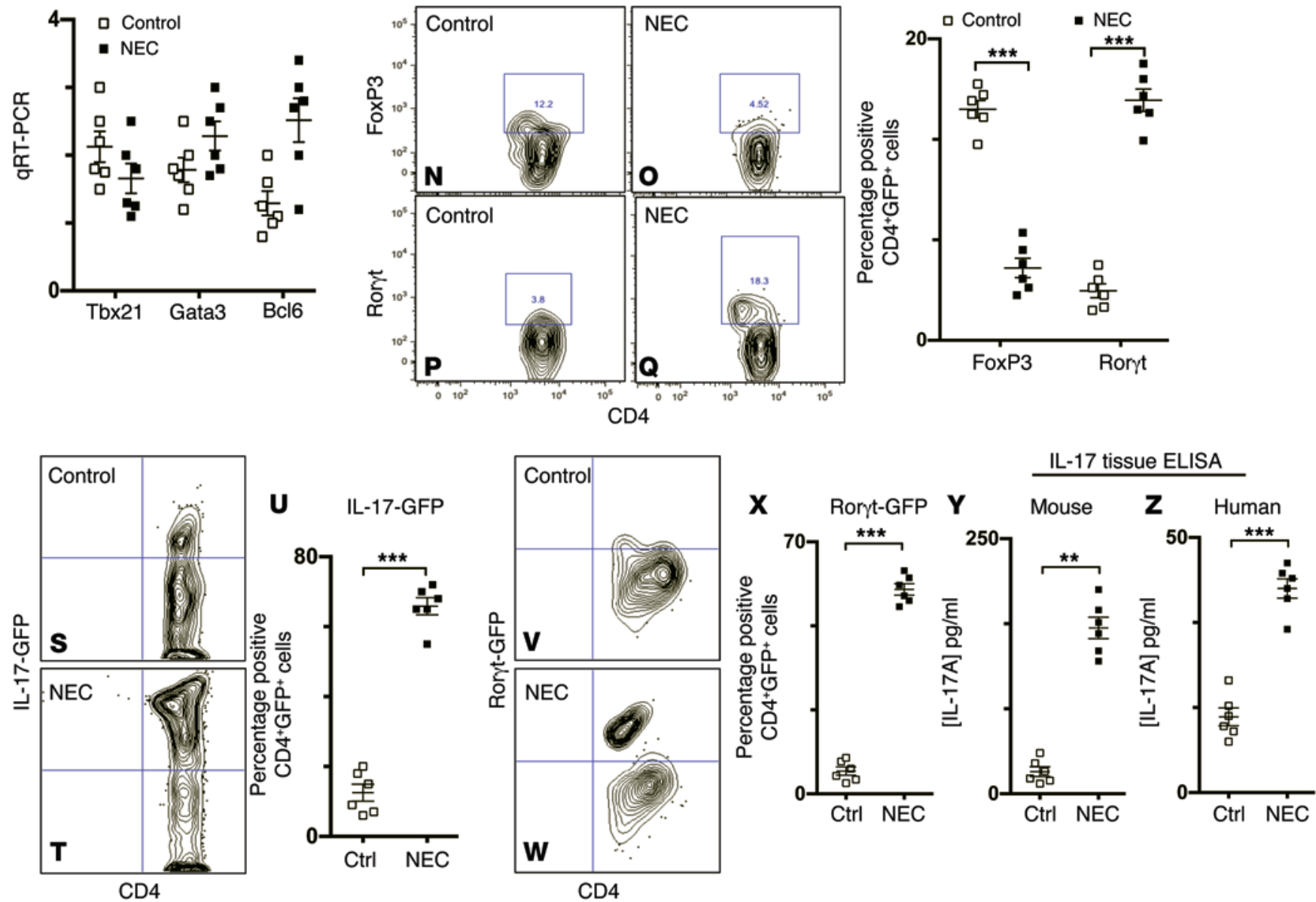
Figure 1. Development of NEC is associated with induction of Th17 cells and reduction in Tregs in the newborn intestine of mice and humans. (A-H) Representative confocal micrographs from sections of the terminal ileum in mouse (A-D) and human infant (E-H) with or without NEC, immunostained for CD3 or CD4 as indicated. Characterization of the immune cell infiltrate in the lamina propria in mouse (I) and human (J) is shown. Scale bars: $10 \mu \mathrm{m}$. (K-M) qRT-PCR expression of the lamina propria CD4+ ${ }^{+}$cells in mice with and without NEC for the indicated lymphocyte transcription factors in murine $\mathrm{CD}^{+} \mathrm{T}$ cells. Ctrl, control. (N-R) Flow cytometric analysis of Foxp3 $3^{+}\left(\mathbf{N}\right.$ and $\mathbf{0}$ ) or Ror $\mathrm{t}^{+}$( $\mathbf{P}$ and $\mathbf{Q}$ ) cells in the lamina propria of mice with and without NEC; quantification is shown in R. (S-W) Flow cytometric analysis of GFP+CD4+ cells in the small intestine of mice without ( $\mathbf{S}$ and $\mathbf{V}$ ) and with ( $\mathbf{T}$ and $\mathbf{W}$ ) NEC that expressed GFP either on the IL-17 promoter $(\mathbf{S}-\mathbf{U})$ or the Roryt promoter $(\mathbf{V}-\mathbf{X})$; quantification is shown in $\mathbf{U}$ and $\mathbf{X}$. ( $\mathbf{Y}$ and $\mathbf{Z}$ ) IL-17A ELISA in the intestinal lysates of mouse $(\mathbf{Y})$ and human (Z). Human data are representative of 6 individuals for flow cytometry, 4 individuals for immunohistochemistry, and 6 for cytokine analysis. Mouse data are representative of 3 independent experiments with 5 mice per group in all cases. Error bars indicate mean $\pm \mathrm{SD}$. ${ }^{* *} P \leq 0.01 ;{ }^{* * *} P \leq 0.001$, Student's $t$ test when comparisons of 2 groups are made, by ANOVA for multiple comparisons.

\section{Results}

The development of NEC requires an influx of lymphocytes into the lamina propria of the newborn mouse and human intestine. We first sought to determine the composition of leukocytes within the lamina propria of mice and humans with NEC. As shown in Figure 1, the development of NEC is associated with an influx of lymphocytes (CD3 in mouse and CD4 in human). Flow cytometry (Figure 1, I and J) and transcription factor profiling (Figure 1, K-R) revealed a significant increase in $\mathrm{CD}^{+} \mathrm{T}$ cells that express RARrelated orphan receptor $\gamma$, isoform $\mathrm{t}(\mathrm{ROR} \gamma \mathrm{t})$ and a reduction in $\mathrm{CD}^{+}{ }^{+} \mathrm{Foxp}^{+}$Tregs as compared with controls. Of note, all of the $\mathrm{CD}^{+}$cells identified are $\mathrm{CD}^{+} 5^{+} \mathrm{CD}^{+}$, i.e., conventional $\mathrm{T}$ cells, excluding group 3 innate lymphoid cells (ILC3s), which are CD3 negative $(22,23)$. The finding that $\mathrm{CD} 4^{+} \mathrm{Th} 17$ cells are enriched in the intestinal mucosa in mouse NEC was validated in 2 separate strains of Th17 cell reporter mice, namely IL-17-GFP mice (Figure $1, \mathrm{~S}-\mathrm{U})$, which reveal a significant increase in $\mathrm{IL}-17^{+}$lymphocytes compared with controls, and ROR $\gamma \mathrm{t}-\mathrm{GFP}$ mice (Figure 1, V-X), which demonstrate increased ROR $\gamma \mathrm{t}^{+}$lymphocytes compared with controls. Furthermore, levels of IL-17A in intestinal tissue lysates from mouse and human NEC were significantly increased compared with control tissues, as revealed by ELISA (Figure 1, $\mathrm{Y}$ and $\mathrm{Z}$ ), supporting a potential functional role for Th17 cells in NEC. Taken together, these data demonstrate that both mouse and human NEC are associated with an increase in $\mathrm{CD} 4^{+}$Th17 cells and a decrease in Tregs in the intestinal mucosa.

To assess whether $\mathrm{T}$ lymphocytes are required for the development of NEC, we next induced NEC in recombination activating gene 1-deficient $\left(\right.$ Rag1 $\left.^{--}\right)$mice, which are deficient in functional $\mathrm{T}$ and B cells (24), and found these mice to be significantly protected from NEC development, as manifested by reduced injury severity and mucosal cytokine expression compared with their WT counterparts (Figure 2, A-H). Importantly, the adoptive transfer of the naive $\mathrm{CD} 4^{+} \mathrm{T}$ cells isolated from age-matched WT mice to Rag1 $1^{-1-}$ mice prior to NEC induction restored the susceptibility of these mice to developing NEC (Figure 2, E-H), confirming that T cells exert a primary as opposed to a secondary role in the pathogenesis of this disease. To further investigate the notion that the infil- trating $\mathrm{CD} 4^{+} \mathrm{T}$ cells play a causative role in disease development, we isolated $\mathrm{CD} 4^{+} \mathrm{T}$ cells from WT mice with NEC and adoptively transferred these cells into young Rag1 ${ }^{-/}$recipient mice. The successful transfer and repopulation of these $\mathrm{T}$ cells (which we now refer to as NEC-T cells) into the Rag1 $1^{-/}$mice is shown in Figure 2, $\mathrm{R}$ and S. Strikingly, transfer of these NEC-T cells induced spontaneous inflammation 72 hours later in the recipient mice, as shown by elevated inflammatory cytokines and the emergence of intestinal damage, as measured by increased mucosal 3-nitrotyrosine staining compared with controls (Figure 2, I-L). Evidence that we had repopulated the lamina propria with the $\mathrm{T}$ cells from the appropriate respective group is provided in Figure 2, P-S. Taken together, these findings reveal that the pathogenesis of NEC requires an influx of $\mathrm{CD} 4^{+}$lymphocytes. We next sought to determine the mechanisms by which these $\mathrm{CD} 4^{+} \mathrm{T}$ cells are recruited to the newborn gut in the pathogenesis of NEC.

The elevated expression of TLR 4 in the newborn intestinal epithelium regulates the recruitment and differentiation of $T$ cells in the newborn intestine. We have previously shown that the development of mucosal inflammation in NEC is influenced by the expression of the receptor for lipopolysaccharide TLR4 on the intestinal epithelium, as mice lacking TLR4 were found to be protected from NEC development (6), while mice that selectively overexpress TLR4 in the intestinal epithelium develop severe NEC (TLR4 $4^{\mathrm{IEC}-\text { over) }}$ (8). Having shown that influx of $\mathrm{CD}^{+}$cells and reduction in Tregs play critical roles in NEC development (Figure 1), we next sought to explore whether TLR4 expression in the intestinal epithelium influenced the composition of $\mathrm{T}$ cells within the lamina propria. As can be seen in Figure 3, A-C, the lack of TLR4 on the intestinal epithelium (TLR4 ${ }^{\mathrm{IIEC}}$ ) prevented the recruitment of $\mathrm{T}$ cells as compared with what occurred in WT mice (Figure 3A), while mice in which TLR4 was selectively expressed on the intestinal epithelium (TLR4 ${ }^{\text {IEC-over) }}$ showed a robust influx of $\mathrm{CD} 4^{+} \mathrm{T}$ cells (Figure $3 \mathrm{~A}$ ). Furthermore, TLR $4^{\triangle \mathrm{IEC}}$ mice showed a reduction in the expression of the Th17 lineage transcription factor RAR-related orphan receptor C (RORC) and an increase in Foxp $3^{+}$Tregs (Figure 3, B and C), findings which were reversed in TLR $4^{\mathrm{IEC}-\text { over }}$ mice (Figure 3, B and C). Taken together, these findings indicate that TLR4 expression in the intestinal epithelium influences the recruitment and composition of $\mathrm{T}$ cells in the intestinal mucosa.

Having shown that TLR4 plays a critical role in mediating the recruitment and differentiation of $\mathrm{T}$ cells in the intestinal mucosa of mice, we next sought to determine the potential mechanisms involved. In other systems, the recruitment of $\mathrm{T}$ cells into the intestinal mucosa is governed by surface expression of the chemokine receptor 9 (CCR9) on lymphocytes and secretion of the cognate chemokine ligand 25 (CCL25) by the intestinal epithelium $(25,26)$. As shown in Figure 3, CCL25 was found to be expressed on the intestinal epithelium and also to be increased in both human and mouse NEC, as shown by immunohistochemical staining of tissue sections (Figure $3, \mathrm{D}-\mathrm{G}$ ) and quantitative reverse-transcriptase PCR (qRT-PCR) (Figure 3, H, J). Furthermore, incubation of cultured intestinal enteroids from neonatal WT mice with LPS resulted in CCL25 secretion, as measured by ELISA of the culture supernatant (Figure 3I). This was not seen in adult tissue, nor was it seen in explants isolated from TLR $4^{\triangle \mathrm{AICC}}$ mice (Figure 3I). In order to define whether the expression of 

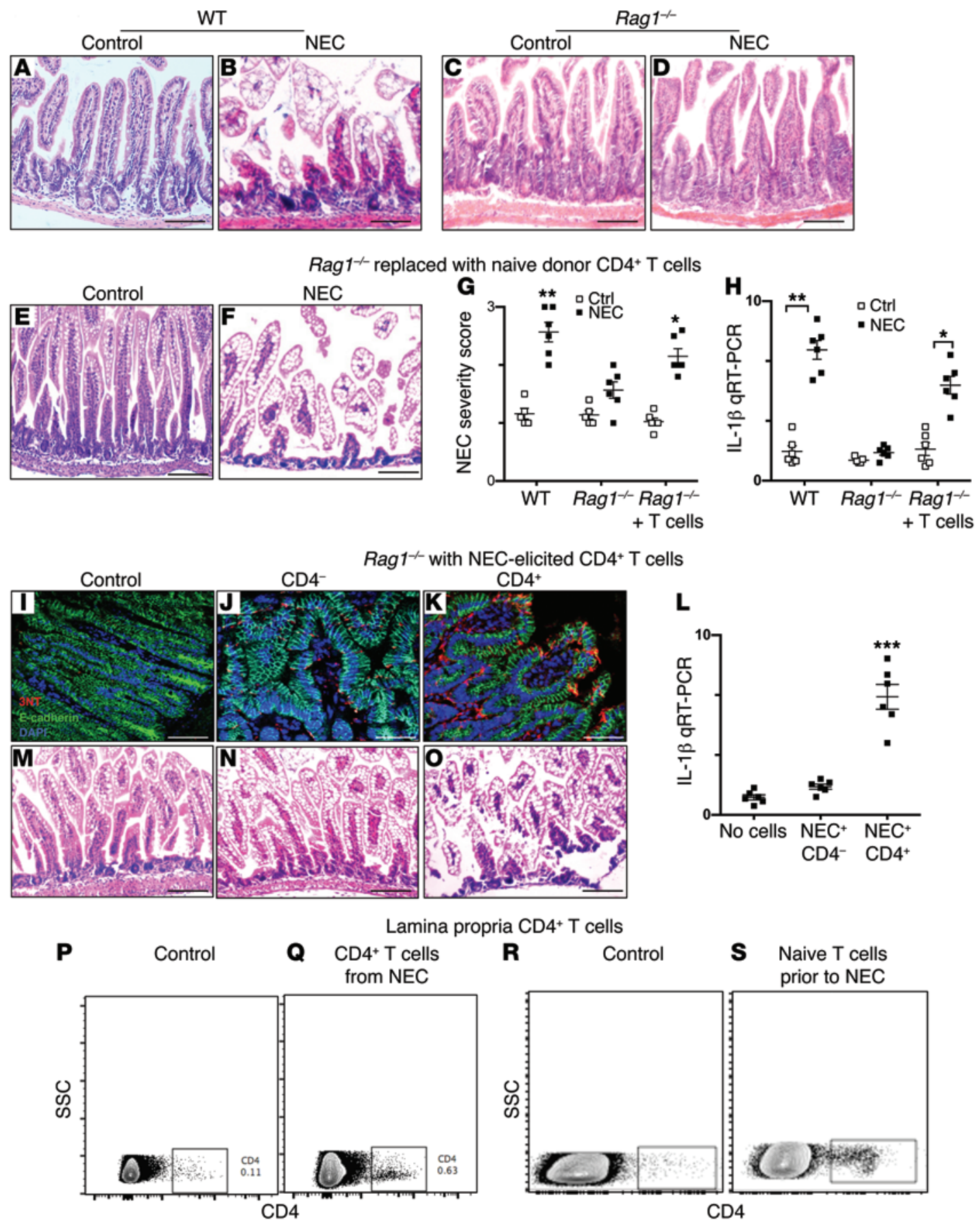

Figure 2. NEC development requires an influx of lymphocytes into the lamina propria of the newborn mouse and human intestine. (A-F) Representative H\&E-stained histomicrographs of the terminal ileum from WT (A and $\mathbf{B}), \operatorname{Rag}^{1 /-}(\mathbf{C}$ and $\mathbf{D})$, or $\operatorname{Rag}^{1 /-}$ mice that had been repopulated with naive donor CD4 ${ }^{+} \mathrm{T}$ cells $(\mathbf{E}$ and $\mathbf{F})$ and were either control $(\mathbf{A}, \mathbf{C}$, and $\mathbf{E})$ or induced to develop NEC (B, D, and F). Scale bars: $50 \mu \mathrm{m}$. (G and $\left.\mathbf{H}\right)$ NEC severity score (C) and expression of IL-1 $\beta$ in the terminal ileum (H) for the indicated groups. (I-K, $\mathbf{M - 0}$ ) Representative confocal micrographs for DAPI (blue), E-cadherin (green), and 3-nitrotyrosine (red) (I-K) and H\&E-stained sections (M-O) of the terminal ileum in mice 48 hours after the injection of CD4 ${ }^{+}$cells elicited from

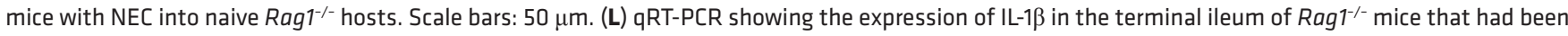
injected either with no cells or with either $\mathrm{CD}^{-}$- or $\mathrm{CD}^{+}$cells from the terminal ileum of mice with NEC. (P-S) Flow cytometry showing the distribution of CD4 ${ }^{+} \mathrm{T}$ cells from mice pertaining to experiments shown in $\mathbf{E}$ and $\mathbf{F}$ or $\mathbf{I}-\mathbf{O}$ above. Mouse data are representative of 3 independent experiments with 5 or more mice per group, as shown. Error bars indicate mean $\pm \mathrm{SD}$. ${ }^{*} P \leq 0.05 ;{ }^{* *} P \leq 0.01$; ${ }^{* *} P \leq 0.001$, by ANOVA for multiple comparisons.

CCL25 in response to TLR4 signaling plays a role in NEC pathogenesis, we inhibited CCL25 in vivo using a lentiviral approach, which resulted in decreased tissue injury (Figure 3, K-M), reduced expression of the proinflammatory cytokine inducible nitric oxide synthase (iNOS) (Figure $3 \mathrm{~N}$ ), and reduced NEC severity score (Figure 3O). Most significantly, CCL25 knockdown resulted in significantly impaired recruitment of total $\mathrm{CD}^{+} \mathrm{T}$ cells into the intestinal mucosa (Figure 3P). Evidence for successful CCL25 
knockdown is shown in Figure 3Q. Of note, we examined CCL2O and its receptor CCR6, which can also drive lymphocyte migration into the intestinal mucosa (27), and did not observe any transcriptional changes (not shown). Taken together, these findings illustrate that TLR4 directs the proinflammatory recruitment of $\mathrm{T}$ (Th17) cells into the intestinal mucosa of mice via CCL25. We next sought to define how these $\mathrm{T}$ cells cause intestinal mucosal injury leading to NEC and therefore focused on the potential role of IL-17, the major inflammatory cytokine of Th17 cells.

$I L-17$ release causes intestinal mucosal injury in the pathogenesis of NEC. We next sought to understand how the CD4 $4^{+}$Th17 cells that were recruited to the newborn intestinal mucosa in a TLR4dependent manner could induce NEC and thus focused on the biological consequences of the IL-17 being secreted by these cells. First, we noted that expression of the IL-17 receptor IL17RA was significantly increased during mouse and human NEC, as revealed by immunohistochemistry (Figure 4, A-F), qRT-PCR (Figure 4, G and I), and SDS-PAGE of intestinal lysates (Figure $4, \mathrm{H}$ and $\mathrm{J}$ ), potentially rendering the tissue more responsive to IL-17 cytokines. Importantly, the expression of IL-17RA in NEC was found to be dependent on the expression of TLR4 on the intestinal epithelium, as the deletion of TLR4 from the intestinal epithelium (i.e., induction of NEC in TLR4 ${ }^{\triangle I E C}$ mice) prevented the upregulation of IL-17RA, while the induction of NEC in TLR4 ${ }^{\text {IEC-over }}$ mice resulted in significant upregulation of IL-17RA (Figure 4, A-H). In seeking to understand how the release of IL-17 in the intestinal mucosa could lead to intestinal injury seen in NEC, we observed that the exposure of IEC- 6 enterocytes which are immature crypt-derived cells (28) and have been shown to express TLR4 at high levels, comparable to those seen in the newborn gut $(11,29,30)$ - to IL-17A caused a loss of intercellular tight junctions (Figure 4, K and L), reduced proliferation (Figure 4, M and N), and increased apoptosis (Figure 4, O and $\mathrm{P})$ in these enterocytes, findings that we and others have shown to be precursors of intestinal mucosal injury in NEC $(11,14)$. In support of these findings, we noted that in primary enteroid cultures that had been harvested from newborn mice, the addition of IL-17A caused a loss of tight junctions in a time-dependent manner (Supplemental Figure 1, A-H; supplemental material available online with this article; doi:10.1172/JCI83356DS1) as well as increased apoptosis and necrosis (Supplemental Figure 1, $\mathrm{I}-\mathrm{M})$. These findings were also observed in vivo, as the intraperitoneal injection of newborn mice with purified IL-17A led to the loss of tight junctions between cells within the villi (Figure 4, Q and R), reduced enterocyte proliferation (Figure 4, E, S, and T), and increased crypt apoptosis (Figure 4, $\mathrm{U}$ and $\mathrm{V}$, and quantification in Figure 4, W and Y). Evidence that IL-17 signaling leads to mucosal injury in NEC via effects on the intestinal epithelium is shown in Figure 5, in which treatment of mice with anti-IL-17R antibody is shown to have reversed the disruptive effects on tight junctions, restored proliferation, and reduced apoptosis, leading to a reduction in the severity of NEC (Figure 5, A-O). Taken together, these findings reveal that IL-17 release plays a critical role in the pathogenesis of NEC via effects on the intestinal epithelium. We next sought to assess how the T cells were induced to become proinflammatory Th17 cells in the context of the premature intestine.
The inflammatory microenvironment of the premature intestine leads to an induction of Th17 cells and reduction in Tregs. In the next series of studies, we sought to assess how naive T cells could polarize into a predominantly $\mathrm{CD} 4^{+} \mathrm{Th} 17$ phenotype with a reduction in Tregs in the pathogenesis of NEC. As shown in Figure 6A, the intestinal mucosa of the premature human is characterized by an increased expression of TLR4, as we have shown previously $(8,17$, 31). We now observe that, compared with the full-term intestine, the premature human gut is also characterized by an increase in the expression of proinflammatory cytokines that are known to be pivotal in the differentiation of naive T cells into Th17 cells, namely IL-22 and IL-6 (Figure 6, B and C), as well as an increase in the expression of pSTAT3 (Figure 6E), which is a critical factor in T cell differentiation toward a Th17 phenotype (32). Importantly, while these cytokines and the expression of PSTAT3 were high in the fetal bowel and stayed high in patients with NEC, they returned to low levels when NEC had healed (Figure 6, A-E), reflecting that their elevation predisposes a premature infant to NEC, as opposed to a response to the inflammation (Figure 6, A-E). In support of this possibility, we observed a similar increase in the expression of TLR4 as well as the proinflammatory molecules leading to Th17 induction (namely IL-22, IL-6, and pSTAT3) in mice with NEC compared with control mice (Figure 6, F-J). The induction of these Th17 cellinducing molecules was elevated in NEC in a TLR4-dependent manner, as the induction of NEC in TLR $4^{\triangle I E C}$ mice prevented their increase (Figure 6, F-J). We further note that the expression of Th17 lymphocytes was significantly higher in newborn versus adult intestine (Supplemental Figure 2), consistent with the elevation in TLR4 expression in the newborn versus adult gut (Figure 6A). To evaluate directly whether the pSTAT3-rich milieu of the premature gut may play a key role in $\mathrm{T}$ cell polarization, we next treated mice with the STAT3 inhibitor WP1066 prior to the induction of NEC and determined that the severity of NEC was significantly reduced (Figure 6, K-W) and that T cell polarization was restored toward an increase in Tregs with a reduction in $\mathrm{CD}^{+}$Th17 cells (Figure 6U), with a concomitant reduction in IL-17 (Figure 6W). Taken together, these findings suggest that the proinflammatory, pSTAT3 rich environment of the premature gut predisposes to the induction of Th17 cells that leads to the development of NEC.

Oral formula modification can restore the balance of lymphocytes in the premature intestine and attenuate the severity of experimental NEC. In the final series of studies, we sought to determine whether manipulation of the oral formula could restore the $\mathrm{T}$ cell composition of the premature intestinal mucosa toward a predominantly Treg phenotype and thus attenuate NEC severity. In other systems, the administration of all-trans retinoic acid (ATRA) has been shown to induce Treg populations and limit CD $4^{+}$Th17 cells. suggesting its possible value in this setting (33). Strikingly, as shown in Figure 6, treatment of mice with ATRA resulted in a significant reduction in NEC severity (Figure 6, N, S, and T), a marked increase in Tregs and a decrease in $\mathrm{CD} 4^{+}$Th17 cells (Figure 6V), and a marked attenuation in IL-17 expression (Figure 6, $\mathrm{D}$ and $\mathrm{W})$. We note that the expression of TLR4 in the intestine of newborn mice with and without NEC was not influenced by the administration of ATRA, indicating that ATRA administration protects against NEC severity through pathways downstream of TLR4 expression, as the above findings reveal (Supplemental Fig- 

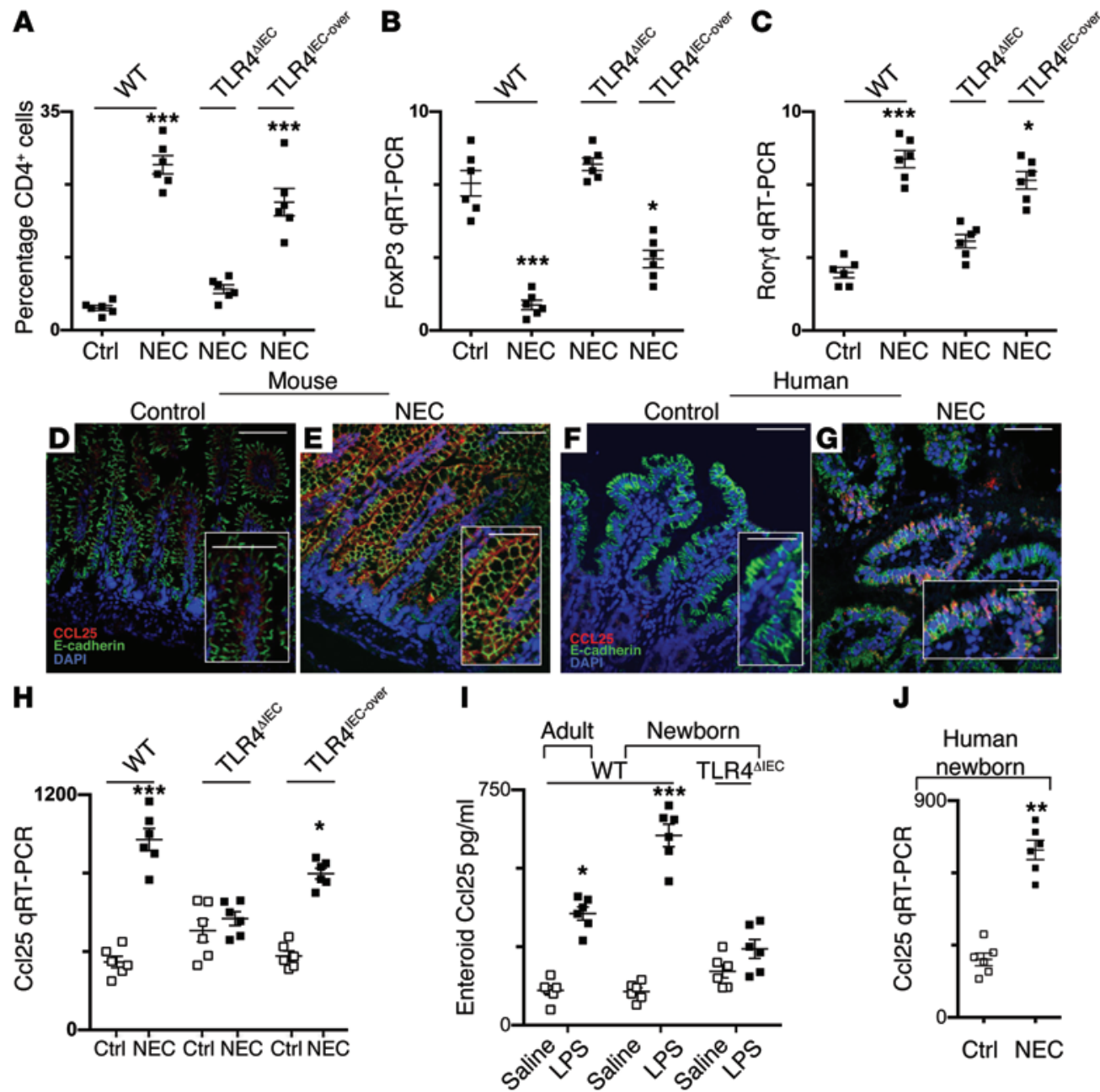

J
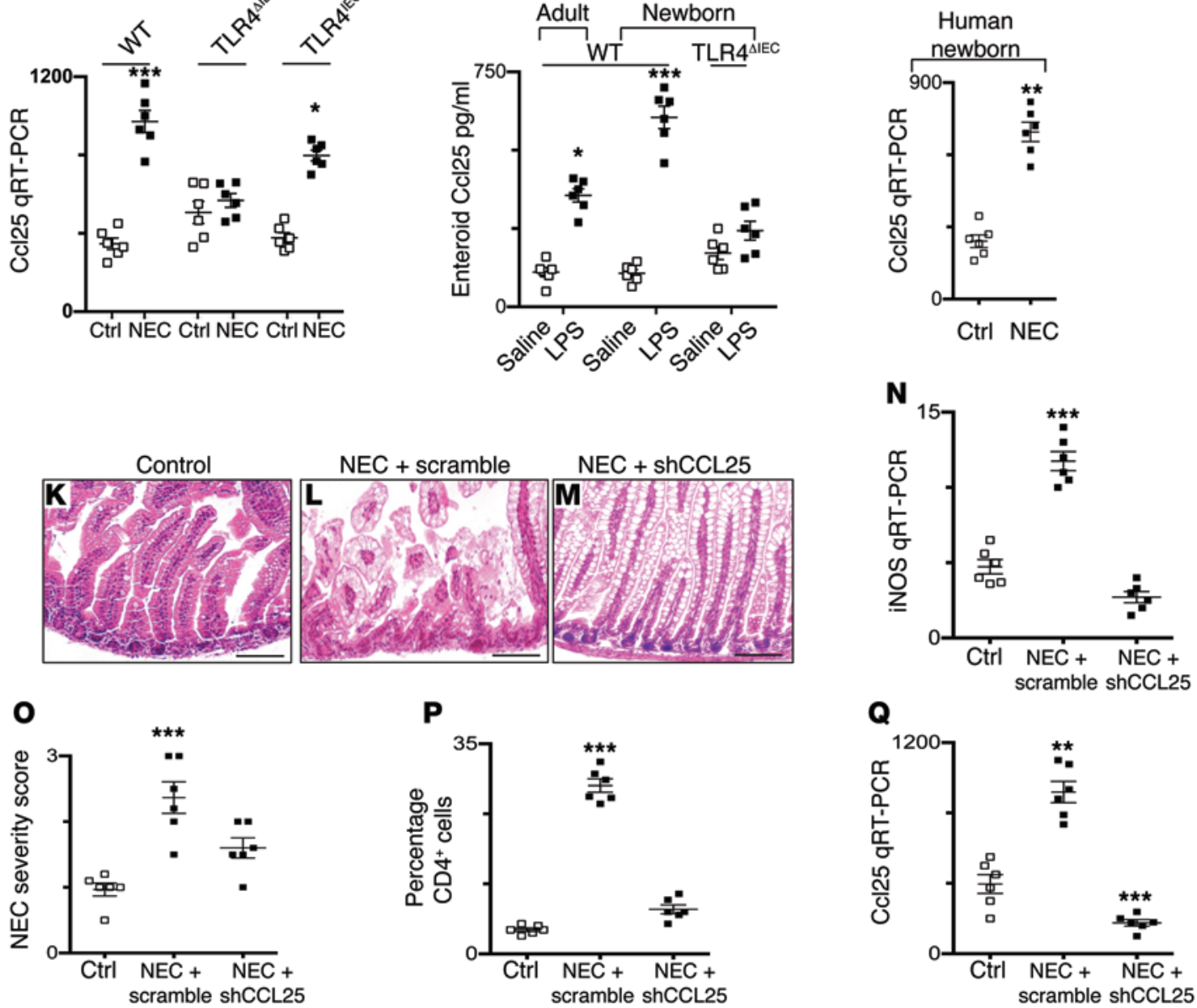
Figure 3. TLR4-dependent CCL25 release recruits pathogenic $\mathrm{CD4}^{+} \mathrm{T}$ cells to the gut, leading to the development of NEC. (A-C) Flow cytometric analysis of $\mathrm{CD}^{+}{ }^{+}$T cells (A), qRT-PCR for Foxp3 (B), and ROR $\gamma \mathrm{t}(\mathbf{C})$ in either WT mice, mice lacking TLR4 in the intestinal epithelium (TLR4 ${ }^{\triangle I E C}$ ), or mice overexpressing TLR4 in the intestinal epithelium (TLR4 ${ }^{\mathrm{IEC}-\text { over }}$ ). (D-C) Representative confocal micrographs of the terminal ileum from mouse (D and $\mathbf{E}$ ) or human (F and $\mathbf{G}$ ) without and with NEC stained for CCL25 (red), E-cadherin (green), and nuclei (blue). Scale bars: $50 \mu \mathrm{m}$. (H-J) qRT-PCR for CCL25 in the indicated strain in the presence or absence of NEC as indicated (H); expression of CCL25 in the supernatant by ELISA obtained from cultured enteroids from adult or newborn WT or TLR4 ${ }^{\Delta I E C}$ mice that had been exposed to either saline or LPS (I); qRT-PCR showing expression of CCL25 in the newborn human intestine with or without NEC as indicated (J). (K-M) Representative H\&E sections of the terminal ileum of C57BL/ 6 mice that were either control (K), subjected to NEC after administration of lentivirus with scrambled shRNA (L), or subjected to NEC after administration of shCCL25 lentivirus (M). Scale bars: $50 \mu \mathrm{m}$. Shown are the expression of iNOS in the terminal ileum (N), NEC severity score (0), percentage of CD4 ${ }^{+}$ cells in the lamina propria (P), and expression of CCL25 by qRT-PCR in the indicated groups (Q). Mouse data are representative of at least 4 independent experiments with at least 4 mice per group for the in vitro data and 6 mice per group for in vivo analysis. Error bars indicate mean \pm SD. ${ }^{*} P \leq 0.05,{ }^{* *} P \leq 0.01,{ }^{* *} P \leq 0.001$, by ANOVA for multiple comparisons.

ure 3). Taken together, these findings further illustrate the importance of CD4 $4^{+}$Th17 lymphocytes in the pathogenesis of NEC and raise the possibility that dietary manipulations that pivot the host toward an induction of Tregs and reduction in $\mathrm{CD} 4^{+}$Th17 cells may offer novel preventative or therapeutic approaches for this devastating disease.

\section{Discussion}

The current studies shed light on the mechanisms that lead to the development of NEC, an often fatal inflammatory disease that affects the intestines of the premature infant. Although there has been significant interest in understanding the mechanisms that lead to NEC in recent years (34), there has been very little focus on the nature and role of the inflammatory cells within the intestine in patients who develop this disease. In seeking to address this knowledge gap in the field, we have now observed that the cellular infiltrate in both mouse and human NEC is extremely rich in $\mathrm{CD} 4^{+} \mathrm{T}$ lymphocytes and, in particular, in $\mathrm{CD} 4^{+} \mathrm{Th} 17$ cells (Figure 1), which are able to induce a proinflammatory phenotype in the appropriate context. Moreover, the evidence suggests that these infiltrating $\mathrm{T}$ cells are primary instigators of this disease as opposed to secondary responders, as the transfer of NEC-elicited mucosal $\mathrm{CD} 4^{+} \mathrm{T}$ cells into naive mice was found to spontaneously induce intestinal inflammation and lymphocyte-deficient Rag1-mice were protected from NEC development, while strategies that blocked the IL-17 receptor attenuated NEC severity. Taken together, these findings suggest a novel paradigm in which the accumulation of $\mathrm{CD}^{+} \mathrm{Th} 17$ cells leads to the development of this intestinal inflammatory disease in premature infants.

The current study also provides insights into why the premature gut is particularly susceptible to the development of NEC in the first place. Specifically, we now show that TLR4 is expressed at higher levels in the premature intestinal mucosa as compared with the full-term mucosa and that the increased expression of TLR4 is associated with increased expression of pSTAT3 (Figure 6). The proinflammatory microenvironment that in part defines the premature intestinal epithelium has been noted previously (35, 36), but has not been linked to any effects on $\mathrm{T}$ cell differentiation or polarization within the gut. We now demonstrate that the elevation in PSTAT3 leads to the induction of a Th17 phenotypic response and reduction in Foxp3 ${ }^{+}$Treg cells, as the pharmacologic inhibition of STAT3 led to a reduction in ROR $\gamma \mathrm{t}^{+}$cells, an increase in Foxp $3^{+}$cells, and, most importantly, a reduction in NEC severity. It is noteworthy that the exaggerated expression of TLR 4 in the intestinal epithelium of the premature infant led to an induction of the lymphocyte chemoattractant CCL25 on the intestinal epithelium, while inhibition of CCL25 prevented lymphocyte infiltration and reduced NEC severity (Figure 3), providing a mechanism for the influx of lymphocytes into the premature intestine that occurred initially. In aggregate, these findings led us to propose a model to explain how the induction of proinjurious $\mathrm{CD} 4^{+} \mathrm{Th} 17$ cells and a reduction in Tregs occur in the premature gut. Specifically, we now suggest that the elevated expression of TLR4 that defines the premature intestine leads to the recruitment of lymphocytes via the induction of CCL25, while the TLR4-dependent rise in pSTAT3 induces an increase in ROR $\gamma$ t expression and reduction in Foxp3 induction, resulting in the polarization of $\mathrm{T}$ cells toward a Th17 phenotype. The current data suggest that these factors combine to lead to the proinflammatory cellular infiltrate that is required for the induction of NEC.

We readily acknowledge that, while the recruitment of proinflammatory Th17 cells in response to exaggerated TLR4 signaling provides a partial explanation as to why NEC develops in the premature gut, these findings also raise questions as to why such a pattern of signaling molecules would accumulate in the premature gut in the first place. In seeking to answer this question, we have recently determined that the increased expression of TLR4 in the premature gut reflects a surprising nonimmune role for embryonic TLR4 in the regulation of normal intestinal differentiation (6), a finding supported by the observation that TLR4 is expressed to a great degree on the intestinal stem cells as compared with other cell types and that deletion of TLR4 leads to impaired intestinal stem cell differentiation $(8,37)$. In a similar vein, it is possible that the recruitment of Th17 cells to the premature gut also serves a physiological role that has not yet been completely elucidated and that only becomes pathological under conditions of tonic TLR4 activation by colonizing bacteria. In support of this possibility, previous authors have shown that Th17 cells produce IL-22, which has been shown to participate in mucosal restitution after injury $(8,37)$ as well as in driving the production of granulocyte CSF (G-CSF) and the regulation of normal myeloid cell accumulation in the intestine, which may protect against sepsis (38). Moreover, although Th17 cells may play a largely protective role in various settings $(39,40)$, it is clear that these cells can play a key role in the induction of injury to the gut, as IL-17 knockout mice are resistant to 2,4,6-trinitrobenzenesulfonic acid-induced (TNBSinduced) colitis (41) and monoclonal IL-17 antibody treatment has been shown to be partially effective in patients with inflammatory bowel disease (42). It is noteworthy that, during both human and experimental NEC, we observed an increase in expression of the IL-17 receptor, which may be expected to render the tissue more sensitive to the IL-17 that is produced and may perhaps explain the benefit of IL-17 receptor inhibition in NEC. These findings expand 

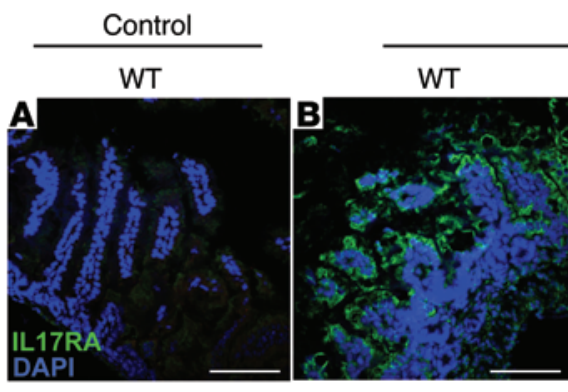

NEC

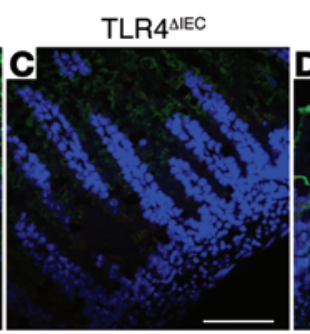

TLR4IEC-over
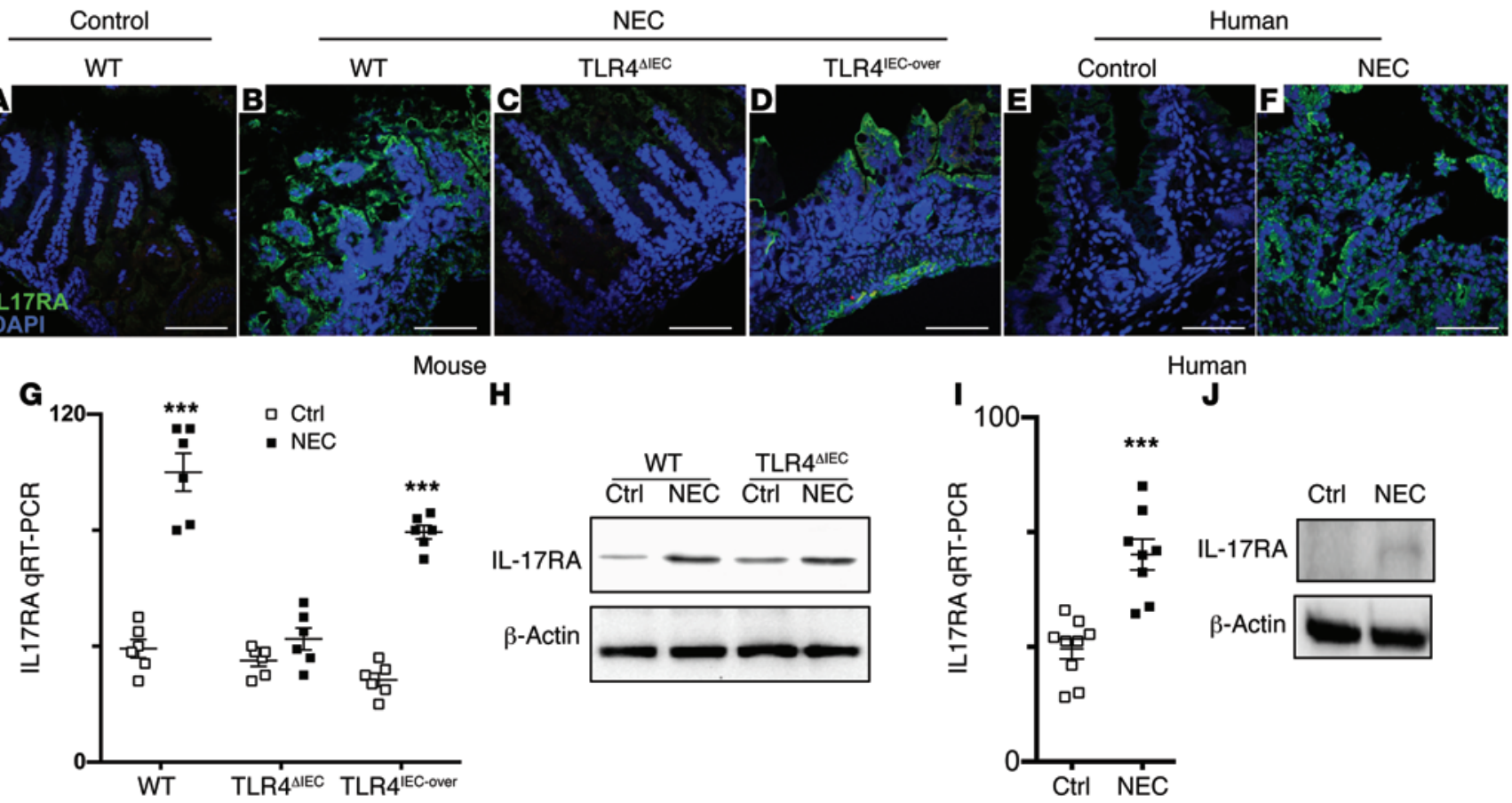

H

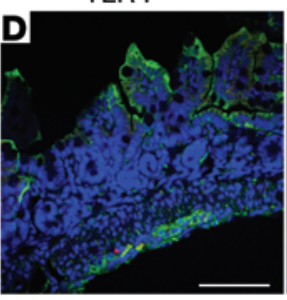

Human
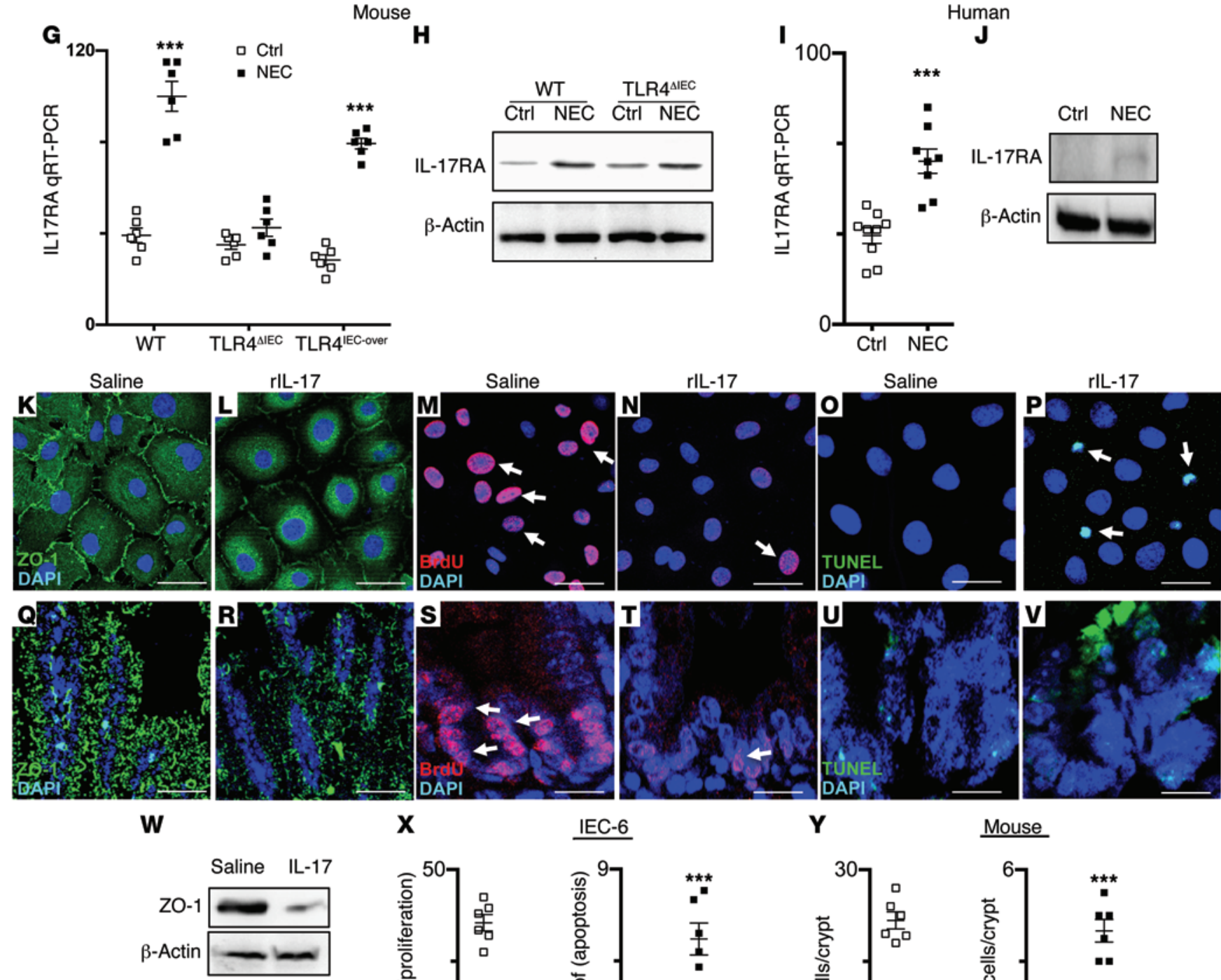

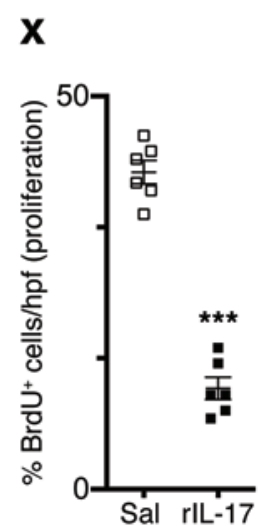

$\mathbf{X}$

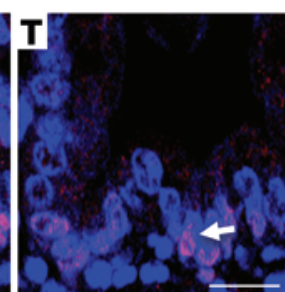

IEC-6

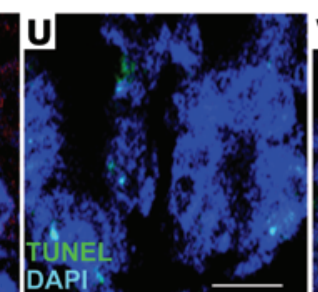

$\mathbf{Y}$

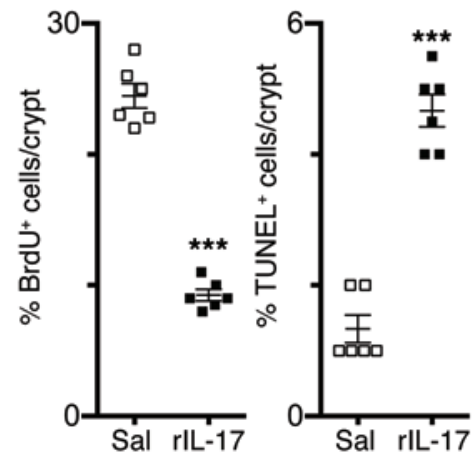


Figure 4. TLR4-dependent release of IL-17 during NEC causes intestinal mucosal injury. (A-F) Representative confocal micrographs from the terminal ileum of mice of the indicated strains $(\mathbf{A}-\mathbf{D})$ and humans ( $\mathbf{E}$ and F) without and with NEC that was immunostained for IL-17RA (green) and DAPI (blue). Scale bars: $50 \mu \mathrm{m}$. (G-J) qRT-PCR showing the expression of IL-17RA in mouse of the indicated strain (G) or human (I) intestine with or without NEC as indicated. SDS-PAGE showing the expression of IL17-R in the intestine of the indicated strain of mouse $(\mathbf{H})$ or of human $(\mathrm{J})$ with or without NEC. (K-V) Representative confocal micrographs of IEC- 6 cells (100 ng/ml, K-P) or the terminal intestine of WT mice $(0.5 \mu \mathrm{g} / \mathrm{kg}, \mathbf{Q}-\mathbf{V})$ that had been treated with IL-17 and stained for ZO-1 (K, L, Q, and $\mathbf{R})$, $\operatorname{BrdU}(\mathbf{M}, \mathbf{N}, \mathbf{S}$, and $\mathbf{T}$, arrows show dividing cells), or TUNEL (O, P, U, and V), arrows show apoptotic cells). Scale bars: $50 \mu \mathrm{m}$. (W and $\mathbf{Y}$ ) SDS-PACE showing the expression of ZO- 1 in IEC- 6 cells; blots were stripped and probed for $\beta$-actin (W). (X and $\mathbf{Y}$ ) Quantification of BrdU-positive cells, TUNEL-positive cells per high-power field in IEC-6 cells $(\mathbf{X})$ and mice $(\mathbf{Y})$. Mouse data are representative of 3 independent experiments with at least 4 mice per group. Error bars indicate mean $\pm \mathrm{SD}$. ${ }^{* *} P \leq 0.001$. Comparisons between 2 groups were by Student's $t$ test and for multiple groups were by ANOVA.

our knowledge of the role of Th17 in the development of mucosal injury and extend the findings of others regarding the pleiotropic role for these cells (43-47), suggesting that the timing and extent of IL-17 receptor expression may play important roles in determining whether injury or protection occurs and provide a strong rationale for the use of IL-17 inhibitory strategies in patients with NEC.

Of the various findings from the current study, one of the most potentially translatable to therapeutic intervention is the observation that the dietary administration of the active metabolite of vitamin A, retinoic acid, can attenuate NEC severity (Figure 6). Retinoic acid has achieved marked attention recently, in part through its effects in reducing numbers of $\mathrm{CD} 4^{+} \mathrm{Th} 17$ cells while concomitantly increasing numbers of Tregs and thus restoring inflamed tissue to health (33). Retinoic acid functions by binding to the nuclear retinoic acid receptor (RAR), thus stabilizing the transcription of Foxp $3^{+}$and repressing ROR $\gamma \mathrm{t}$ transcription (48, 49). We now show that the administration of ATRA to mice in the model of experimental NEC resulted in discernible protection and also a shift in the balance of $\mathrm{T}$ cell subsets to favor Treg differentiation. These findings provide a potential therapeutic or prophylactic approach for consideration in NEC and also are consistent with previous studies of Treg loss during NEC in other models (50-52). It is thus appealing to consider the possibility that modification of infant feeds with vitamins that can modulate the $\mathrm{CD} 4^{+} \mathrm{T}$ cell helper subsets may have significant benefit in patients with NEC.

In summary, the current study provides evidence that NEC could be considered to be a lymphocyte-mediated disease and that the recruitment of proinjurious lymphocytes requires TLR4 signaling in the intestinal epithelium. Further strategies that restore the balance of tolerant lymphocytes may offer novel approaches for the prevention or treatment of NEC.

\section{Methods}

Cell and enteroid culture, antibodies, and reagents. IEC-6 enterocytes were obtained from ATCC. LPS (E. coli 0111:B4 purified by gel-filtration chromatography, $>99 \%$ pure) was obtained from Sigma-Aldrich. Where indicated, cells were incubated with LPS $(50 \mu \mathrm{g} / \mathrm{ml} \times 6$ hours $)$, recombinant rat IL-17A (Peprotech) $(100 \mathrm{ng} / \mathrm{ml})$, or vehicle alone for 6 hours. Primary intestinal cultures (enteroids) were isolated and maintained according to the methods of Sato et al. (53), which we have modified slightly $(8,54)$, and treated with LPS $(10 \mu \mathrm{g} / \mathrm{ml})$ or IL-17A $(100 \mathrm{ng} / \mathrm{ml}$ ) for measurement of CCL25 secretion by ELISA (R\&D Systems), tight junction distribution by immunoconfocal microscopy (see below), or cell death using the Apoptosis/Necrotic Cell Detection Kit (PromoKine Inc.) according to the manufacturer's instructions.

Mouse and human IL-17A sandwich ELISA analyses were performed according to the manufacturer's instructions (IL-17A human or mouse; eBioscience). Briefly, capture antibody was incubated on 96-well flat-bottomed plates overnight. Plates were washed and blocked ( $5 \%$ fetal calf serum; 1 hour, room temperature) before standards in serial dilution, and samples were added to the plate. The samples and standards were incubated on the plate overnight $\left(4^{\circ} \mathrm{C}\right)$ and washed extensively, followed by incubation with biotinylated detection antibody ( 2 hours, room temperature). Following washes, the enzyme conjugate streptavidin alkaline phosphatase was added to the wells and the enzymatic reaction was stopped after 30 minutes by the addition of an equal volume of $0.2 \mathrm{~N}$ sulphuric acid; color change was read at $450 \mathrm{~nm}$. Data were normalized to the standard using Prism GraphPad software.

Immunohistochemistry and SDS-PAGE. Immunofluorescent evaluation of IEC- 6 enterocytes and the intestine of mouse and human was performed as previously described (55) and assessed using a Zeiss LSM 710 confocal microscope under oil-immersion objectives. Assessment of proliferation was performed as described (10). IEC- 6 cells were first incubated with BrdU-labeling reagent $(10 \mu \mathrm{l} / \mathrm{ml}$ media, Invitrogen) for 6 hours. TUNEL staining was performed on $4 \%$ paraformaldehyde-fixed cells or $5-\mu \mathrm{M}$-thick paraffin sections according to the manufacturer's instructions (Roche Applied Science) as described (8). The number of TUNEL-positive cells was identified by an investigator blinded to the treatment groups using Metamorph software (Molecular Devices Corp.) and expressed as the number of TUNEL-positive cells per high-power field, with more than 50 fields per experiment studied and more than 100 cells per field. For SDSPAGE, blots were probed with the antibodies below as described (8) and were stripped and then reprobed for $\beta$-actin, except in the case of the immunoblot in which ZO-1 expression in mouse intestinal lysates was determined, in which case membranes were simultaneously incubated with rabbit polyclonal anti-ZO-1 (Zymed, catalog 40-2300) and mouse monoclonal anti- $\beta$-actin (GenScript, catalog A00730-200). Other antibodies used included pSTAT3 (Cell Signaling, catalog 9145), STAT3 (Cell Signaling, catalog 8768), and IL17RA (R\&D Systems, Clone 133617, catalog MAB177). Cells were stained for nuclear antigens using the Foxp3 buffer set (eBioscience) according to the manufacturer's instructions. Antibodies used for immunohistochemical staining were as follows: 3-nitrotyrosine (ab61392) and ZO-1 (ab59720) (Abcam); CCL25 (NBP1-40993; Novus Biologicals); CD3 (17A2) and CD4 (RPA-T4) (eBioscience); PCNA (PC10; Santa Cruz Biotechnology Inc.); BrdU (BRD494; Novus Biosciences); E-cadherin (AF748; R\&D Systems); $\beta$-actin (2D1D10; Genscript); and DAPI (Pierce). Where indicated, the anti-IL-17-RC and lamina propria cells were delivered via the intraperitoneal route.

Mice. C57BL/6, Rag1 ${ }^{--}$(RagB6.129S7-Rag1tm1Mom/J), IL-17GFP (C57BL/6-Il17atm1Bcgen/J), and RoR $\gamma \mathrm{t}-$ GFP (B6.129P2[Cg]Rorctm2Litt/J) mice were obtained from the Jackson Laboratory. IL-17 reporter mouse strains were a gift from Jay Kolls (University 

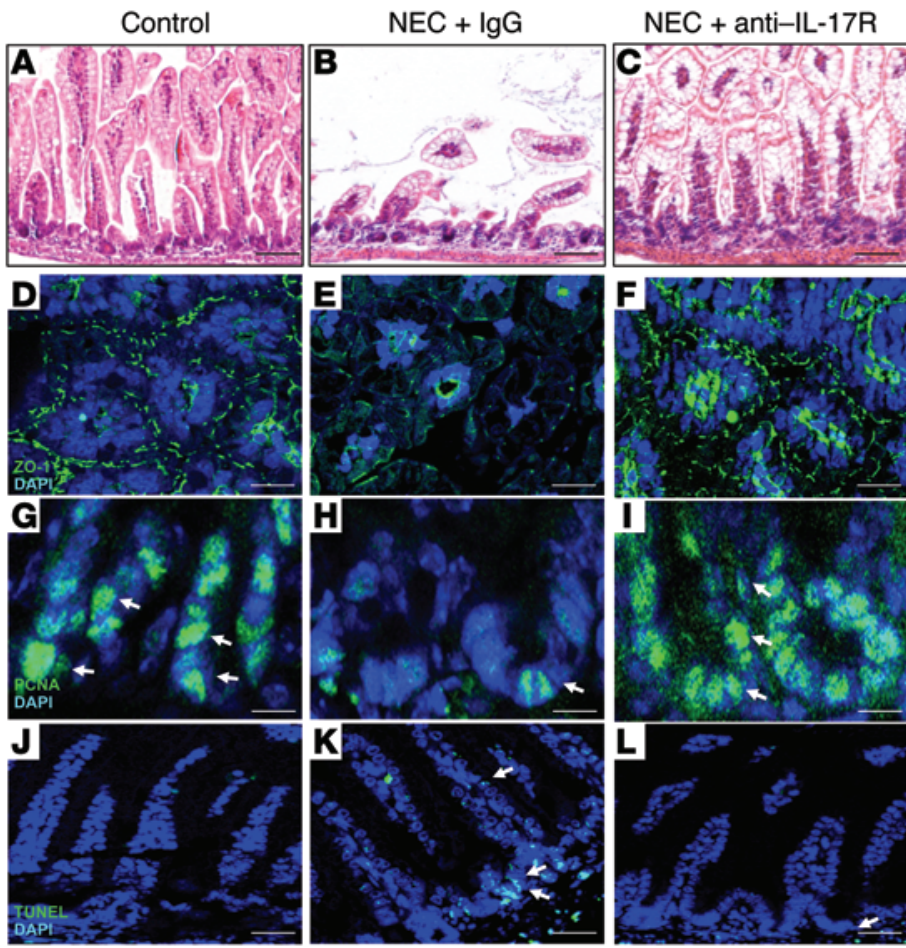

M
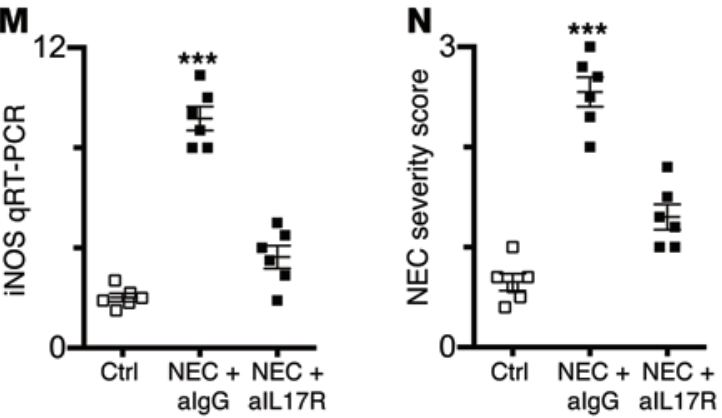

o

NEC

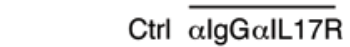

ZO-1

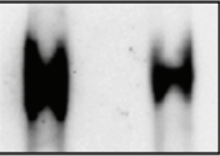

$\beta$-Actin

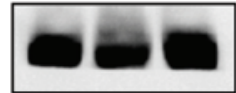

Figure 5. Inhibition of IL-17R reverses mucosal damage in NEC in mice. (A-L) WT mice were either breast fed or induced to develop NEC after injection with IgG or anti-IL-17R as indicated. Shown are representative H\&E micrographs $(\mathbf{A}-\mathbf{C})$ or confocal micrographs stained for DAPI (blue) and ZO-1 (green, D-F), PCNA (green, G-I, arrows show dividing cells), and TUNEL (green, J-L, arrows show apoptotic cells). Scale bars: $10 \mu \mathrm{m}$. (M-0) qRT-PCR showing expression of iNOS in the terminal ileum (M), NEC severity score (N), and SDS-PAGE showing the expression of ZO-1 $(\mathbf{O})$ in the indicated group. Data are representative of 3 separate experiments with at least 4 mice per group. ${ }^{* *} P<0.001$, by ANOVA for multiple comparisons.

of Pittsburgh). Mice in which TLR4 was selectively deleted from the intestinal epithelium (TLR4 ${ }^{\triangle I E C}$ ) (6) and mice selectively expressing TLR4 in intestinal epithelium (TLR4 $4^{\text {IEC-OVER }}$ ) (8) were recently generated in our laboratory.

Induction of NEC. NEC was induced in 7- to 8-day-old mouse pups through the combination of enteral formula, hypoxia $\left(5 \% \mathrm{O}_{2}\right)$, and administration of enteric bacteria from a patient who had developed NEC as described. The infection was validated in a manner that results in patchy necrosis and inflammation of the ileum that closely resembles clinical NEC $(9,11)$. In genetically modified mouse experiments, all mice were backcrossed at least 8 times with C57BL/6. Both sexes were used for experiments with NEC; endotoxemia models utilized males only.

ATRA (Sigma-Aldrich) was dissolved in DMSO and corn oil (1:1 at a concentration of $6 \mathrm{mg} / \mathrm{ml}$ ) and protected from light prior to administration to mice once daily at $50 \mu \mathrm{g} /$ mouse orally for the duration of the
NEC model. Anti-IL-17-RC (R\&D Systems) was reconstituted just prior to intraperitoneal injection at $100 \mathrm{ng} /$ mouse once daily for the duration of the NEC model. WP1066 (Santa Cruz Biotechnology Inc.) was reconstituted in DMSO and administered to mice once daily at $100 \mathrm{mg} / \mathrm{kg}$ by oral gavage for the duration of the NEC model. Breast-fed control mice were administered the same dose of ATRA once daily by oral gavage. For the inhibition of IL-17 during NEC, mice were injected with $100 \mathrm{ng}$ of anti-IL-17-RC or control IgG daily from the first day of NEC onwards. IL-17 blocking was confirmed by PCR for G-CSF and IL-1 $\beta$. For determination of enterocyte proliferation, mice were gavaged with BrdU (10 $\mu \mathrm{l} / \mathrm{g}$ body weight) 24 hours before sacrifice and BrdU was detected as described (37).

To achieve knockdown of the $C c l 25$ gene in vivo, mice were gavage fed twice daily $\left(50 \mu \mathrm{l}\right.$ of $10^{3}-10^{4}$ $\mathrm{PFU} / \mathrm{ml}$ ) with purified lentiviral particles expressing CCL25-shRNA (The RNAi Consortium shRNA clones; Thermo Scientific), which were generated using the ViraPower HiPerform lentiviral expression system (Invitrogen) in permissive HEK293 cells. Knockdown was assessed in mucosal scrapings of the distal ileum by SDS-PAGE 4 days after the initial administration of CCL25-shRNA lentivirus and was not seen in mice treated with control lentivirus expressing scrambled shRNA.

Lamina propria cell isolation. To isolate the cellular infiltrate from the lamina propria of newborn mouse or human, small intestinal samples were cleaned of mesentery, opened longitudinally and finely minced with scissors, and incubated in RPMI containing $10 \%$ fetal bovine serum and 10 $\mathrm{mM}$ dithioerythritol (Sigma-Aldrich) prewarmed to $37^{\circ} \mathrm{C}$. Tissue was incubated for 20 minutes with gentle agitation. Supernatants containing the enterocyte layer were then discarded. Lamina propria leukocytes were then isolated from the remaining tissue digestion $\left(37^{\circ} \mathrm{C}, 40\right.$ minutes) in RPMI, 10\% fetal bovine serum, $100 \mathrm{U} \mathrm{ml}^{-1}$ collagenase (Sigma-Aldrich), and $15 \mu \mathrm{g} / \mathrm{ml}$ DNAse (Sigma-Aldrich) with gentle agitation. Cells were then washed twice in ice-cold PBS with $1 \%$ BSA and filtered through sequential $70-\mu \mathrm{m}$ and $40-\mu \mathrm{m}$ cell strainers. Human tissue was prepared following a similar protocol, with the exception of performing 2 sequential collagenase digests in order to liberate all the cells.

Flow cytometry. Single-cell suspensions were stained with the viability dye Zombie Aqua per the manufacturer's recommendations (BioLegend). Washed cells were then incubated in ice-cold FACS buffer (PBS, 1\% BSA, 0.01\% $\mathrm{NaN}_{3}$ ) with anti-CD16/CD32 (BD Bioscience) to block $\mathrm{Fc}$ receptor binding (20 minutes, $4^{\circ} \mathrm{C}$ ) on mouse cells or Fc receptor block (eBioscience) for human samples. Cells were pelleted by centrifugation and resuspended in optimal concentrations of fluorochrome-conjugated antibodies in ice-cold FACS buffer to stain surface molecules. Intracellular staining was performed using the Foxp3 buffer set. After washing, at least 100,000 live cells per sample 

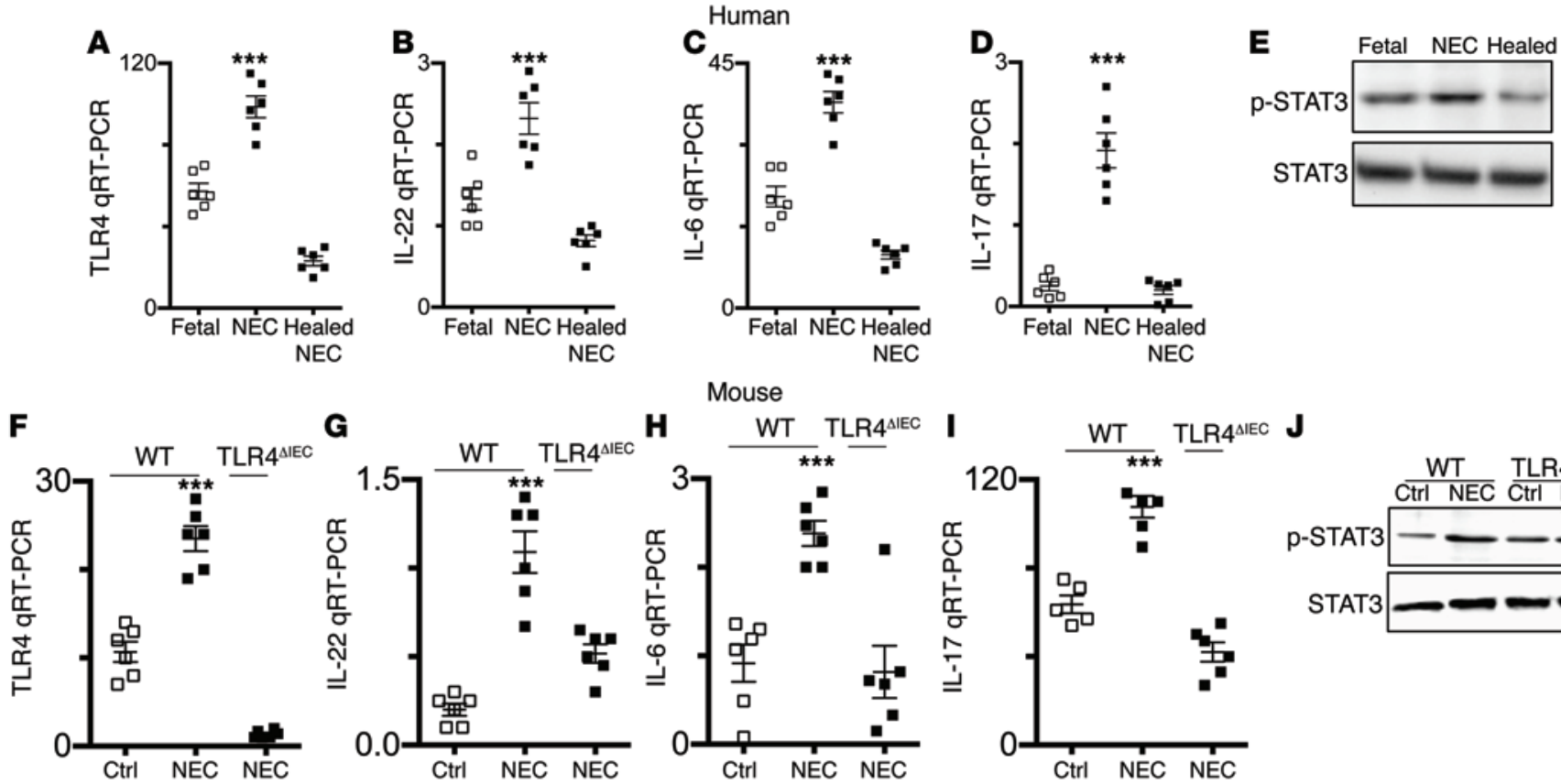

Mouse
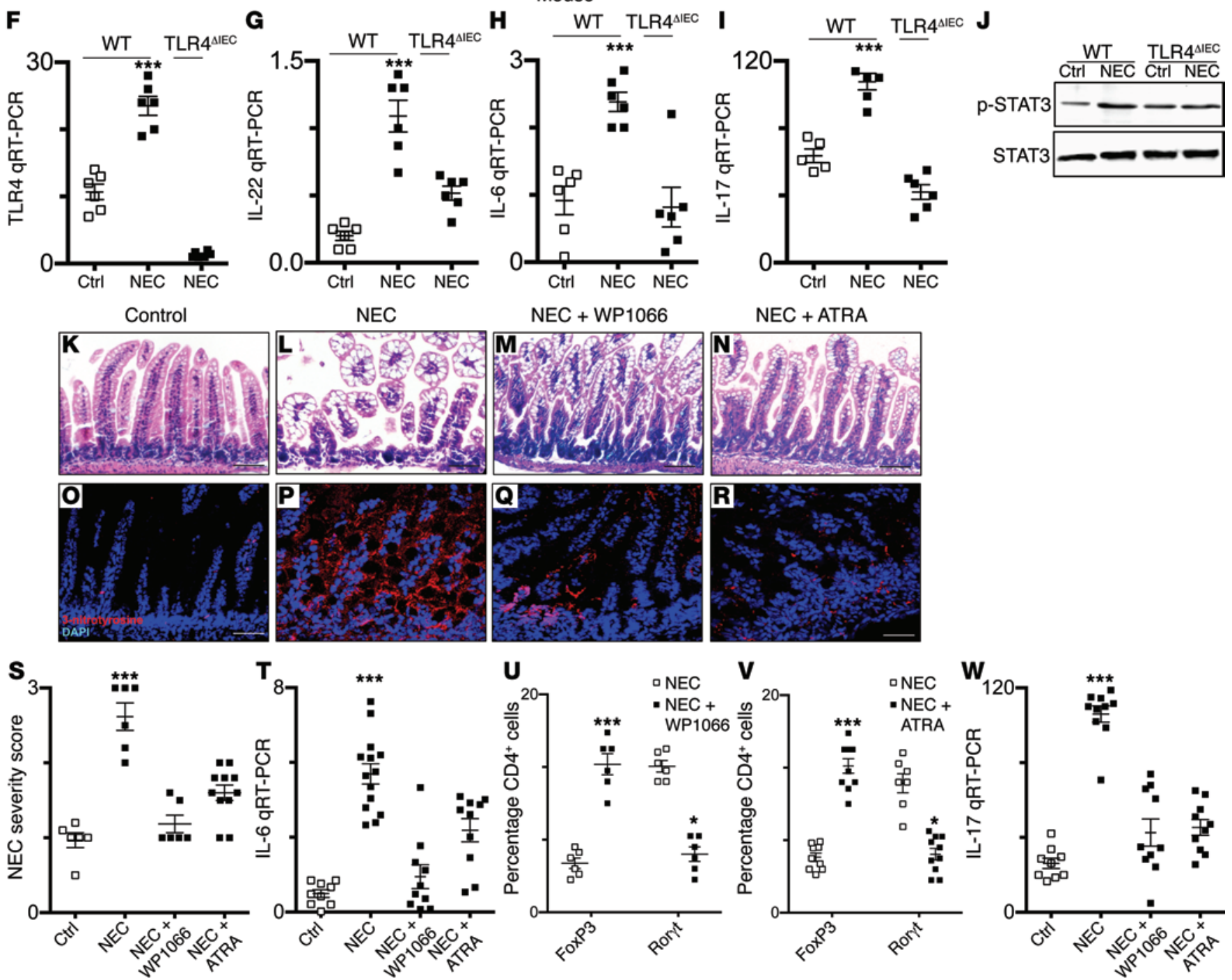

Figure 6. TLR4-dependent proinflammatory environment of the premature intestinal mucosa predisposes to the development of NEC through the reversible STAT3-dependent induction of Th17 cells. (A-J) QRT-PCR showing the expression of the indicated cytokines in human intestine from fetal bowel, active NEC, or healed NEC as indicated (A-D) or from mice without or with NEC from the indicated strain (F-I). (E and J) SDS-PACE showing the expression of pSTAT3 in intestinal lysates from human (E) or mouse (J) as indicated; blots were stripped and reprobed for STAT3. (K-R) Representative H\&E sections (K-N) and confocal micrographs stained for 3-nitrotyrosine (O-R) obtained from terminal ileum of control mice (K and $\mathbf{0})$ or mice induced to develop NEC in the absence ( $\mathbf{L}$ and $\mathbf{P}$ ) or presence of the STAT3 inhibitor WP1066 (100 mg/kg/d oral, $\mathbf{M}$ and $\mathbf{Q})$ or ATRA (50 $\mu \mathrm{g}$ oral daily, $\mathbf{N}$ and $\mathbf{R})$. Scale bars: $50 \mu \mathrm{m}$. (S-W) Panels pertain to the groups of mice in K-R. Shown are the NEC severity score (S), qRT-PCR showing the expression of iNOS (T), flow cytometric analysis showing the percentage of positive CD4+ cells that costained for Foxp3 $3^{+}$or ROR $\gamma \mathrm{t}(\mathbf{U}$ and $\mathbf{V}$ ), and qRT-PCR showing the expression of IL-17 in the terminal ileum of mice as indicated (W). Data are representative of 2 experiments with 10 mice per group. Error bars indicate mean \pm SD. ${ }^{* * *} P \leq 0.001$. ANOVA was used for multiple comparisons. 


\section{Table 1. List of primers}

\begin{tabular}{|c|c|c|c|c|}
\hline Gene & Species & Forward sequence & Reverse sequence & Amplicon size (bp) \\
\hline \multirow[t]{2}{*}{$B C L 6$} & Mouse & GGAAACCCAGTCAGAGTATTCG & GGCAGCGATCACATTTGTATG & 149 \\
\hline & Human & СССТATСССТGTGAAATCTGTG & CTGGCTTTTGTGACGGAAATG & 132 \\
\hline \multirow[t]{2}{*}{ CCl25 } & Mouse & ACCAACGTCTCAGCATGTATG & GGGCAATTTACTCAAGTCACAC & 143 \\
\hline & Rat & TCTCCGGCATGCTAGGCATTATCA & TCACACСCCTCTTCACATCCTTGT & 134 \\
\hline Foxp3 & Mouse & AAGTACСАСАATATGCСACСC & TCTGAAGTAGGCGAACATCC & 154 \\
\hline Gata3 & Human & GTCCTGTGCGAACTGTCACA & TCGGTTTCTGGTCTGGATGC & 154 \\
\hline \multirow[t]{2}{*}{ IL17 } & Mouse & ССAGCTCATCAGGACGCGCA & TCAGGCATCATCGCTGCTGCC & 115 \\
\hline & Human & ССТTGСAАТСТССАССGСАA & GCTGGATGGGGACAGAGTTC & 133 \\
\hline \multirow[t]{2}{*}{ IL17RA } & Mouse & ACAGTTCCCAAGCCAGTTGC & CGGCCAAGATGCCATTGATT & 178 \\
\hline & Human & GCCACACACTCCAGAACCAA & CCAGGTCATCCAGACGATGA & 117 \\
\hline IL1b & Rat & TAGGAAACAGCAATGGTCGGGACA & AGACCTGACTTGGCAGAGGACAAA & 167 \\
\hline \multirow[t]{2}{*}{ IL6 } & Mouse/rat & ССААТTTССААТССТСТССТ & ACCACAGTGAGGAATGTCCA & 182 \\
\hline & Human & TCTCCACAAGCGCCTTCG & CTCAGGGCTGAGATGCCG & 193 \\
\hline \multirow[t]{2}{*}{ iNOS } & Mouse/rat & CTGCTGGTGGTGACAAGCACATTT & ATGTCATGAGCAAAGGCGCAGAAC & 167 \\
\hline & Human & AАTСAGTCСССССАСССССТ & AGTCATCССССТGССССАGT & 143 \\
\hline \multirow[t]{2}{*}{ Rorc } & Mouse & AAGACTGATTTTCTCССССТAG & ТСТАТСССАТСТАССССАСАС & 131 \\
\hline & Human & TGGTGCTGGTTAGGATGTG & GGAGTGGGAGAAGTCAAAGATG & 140 \\
\hline \multirow[t]{2}{*}{ Tbx21 } & Mouse & ACAAGGAAATACGACAGGAGTG & AAAGCCATCAAGTCCCTCTC & 147 \\
\hline & Human & СAAGTTTAATCAGCACCAGACAG & ACACCACGTCCACAAACATC & 121 \\
\hline \multirow[t]{2}{*}{ TLR4 } & Mouse & TTTATTCACAGCCGTTGGTG & CAGAGGATTGTCCTCCCATT & 186 \\
\hline & Human & AAGCCGAAAGGTGATTGTTG & CTGAGCAGGGTCTTCTCCAC & 153 \\
\hline
\end{tabular}

were collected for analysis on a BD LSRII flow cytometer. Data analysis was performed using FlowJo software as previously described (56).

$C D 4^{+} \mathrm{T}$ cell isolation. In order to purify $\mathrm{CD}^{+} \mathrm{T}$ cells for subsequent transcriptional analysis, single-cell suspensions of lamina propria leukocytes obtained as above were incubated with anti-CD4 magnetic beads according to the manufacturer's instructions (Miltenyi Biotec). Cells were then washed and separated by positive selection using an LS column and a MidiMacs magnet (Miltenyi Biotec). CD4 enrichment was confirmed by surface staining for CD4 and flow cytometry. Purity was routinely greater than $85 \%$.

For adoptive transfer studies, recipient naive $\mathrm{Ragl}^{-/-}$mice were then injected with at least $4 \times 10^{6}$ cells. Donor $\mathrm{CD}^{+} \mathrm{T}$ cells were isolated either from naive mice and injected into $\mathrm{Ragl}^{-/-}$recipient pups prior to induction of NEC or from C57BL/6 WT donor mice that had undergone NEC induction. Successful reconstitution of cells was verified by staining mouse lamina propria leukocytes for CD4 at the conclusion of the experiment.

Quantitative real-time PCR. Total RNA was isolated from ileal segments or $\mathrm{CD}^{+}$lamina propria $\mathrm{T}$ cells obtained from control and NEC mouse or human intestine using the Bio-Rad CFX96 Real-Time System (Bio-Rad) (11) and the RNeasy kit (QIAGEN). RNA was reverse transcribed using the QuantiTect Reverse Transcription Kit (QIA-
GEN) as described (9). The expression of the genes listed in Table 1 by qRT-PCR was measured relative to the housekeeping gene RPLO.

Statistics. Where indicated, data were analyzed for statistical significance by 2-tailed Student's $t$ test or ANOVA using Prism 6 software (GraphPad). A $P$ value of less than 0.05 was considered statistically significant, and data are represented as mean \pm SD as indicated. All experiments were repeated at least in triplicate, with at least 5 pups per group for experimental NEC assessed.

Study approval. Mice were housed in specific pathogen-free facility. All animal experiments described in these studies were approved by the University of Pittsburgh or Johns Hopkins University Animal Care and Use Committees and were performed according to the Guide for the Care and Use of Laboratory Animals (8th ed. The National Academies Press. 2011). All human intestinal tissue was obtained and processed as discarded tissue via a waiver of consent with approval from the University of Pittsburgh Institutional Review Board (IRB protocols 0606072 and PRO11110007) and in accordance with University of Pittsburgh anatomical tissue procurement guidelines. Intestinal samples were obtained from human premature neonates undergoing resection for NEC, at the time of stoma closure, or from aborted fetuses and processed as we have described previously $(7,10,16,55,57)$. In the current study, the mean age of patients with NEC was found to be lower than 
that of the controls, but since the generally accepted practice is to perform stoma closure quite soon after the original operation, the majority of "control" bowel was obtained from infants who were still premature (mean age: NEC $26 \pm 4$ weeks vs. $38 \pm 2$ weeks, $P<0.05$ ).

\section{Author contributions}

CEE, CPS, MG, and DJH designed research studies, conducted experiments, acquired data, analyzed data, and wrote the manuscript. JL, HJ, YY, PL, CM, MFB, SW, WBF, DFN, TP, and JAO conducted experiments, acquired data, and analyzed data. DFN did not participate in any studies involving human fetal tissue.

\section{Acknowledgments}

We gratefully acknowledge Jay Kolls for the sharing of IL-17 reporter mouse strains, his expertise, and his helpful review of the manuscript. D.J. Hackam is supported by R01GM078238 and R01DK083752 from the NIH.

Address correspondence to: David J. Hackam, Garrett Professor of Pediatric Surgery, Johns Hopkins University, The Johns Hopkins Hospital, Bloomberg Children's Center, Room 7323, 1800 Orleans Street, Baltimore, Maryland 21287, USA. Phone: 410.955.2717; E-mail: Dhackam1@jhmi.edu.
1. Neu J, Walker WA. Necrotizing enterocolitis. N Engl J Med. 2011;364(3):255-264.

2. Lim JC, Golden JM, Ford HR. Pathogenesis of neonatal necrotizing enterocolitis. Pediatr Surg Int. 2015;31(6):509-518.

3. Lu P, Sodhi CP, Hackam DJ. Toll-like receptor regulation of intestinal development and inflammation in the pathogenesis of necrotizing enterocolitis. Pathophysiology. 2014;21(1):81-93.

4. Besner GE. A pain in the NEC: research challenges and opportunities. JPediatr Surg. 2015;50(1):23-29.

5. Patel RM, Denning PW. Intestinal microbiota and its relationship with necrotizing enterocolitis. Pediatr Res. 2015;78(3):232-238.

6. Sodhi CP, et al. Intestinal epithelial Toll-like receptor 4 regulates goblet cell development and is required for necrotizing enterocolitis in mice. Gastroenterology. 2012;143(3):708-718 e701.

7. Yazji I, et al. Endothelial TLR4 activation impairs intestinal microcirculatory perfusion in necrotizing enterocolitis via eNOS-NOnitrite signaling. Proc Natl Acad Sci U S A. 2013;110(23):9451-9456.

8. Afrazi A, et al. Toll-like receptor 4-mediated endoplasmic reticulum stress in intestinal crypts induces necrotizing enterocolitis. J Biol Chem. 2014;289(14):9584-9599.

9. Good M, et al. Lactobacillus rhamnosus HNOO1 decreases the severity of necrotizing enterocolitis in neonatal mice and preterm piglets: evidence in mice for a role of TLR9. Am J Physiol Gastrointest Liver Physiol. 2014;306(11):G1021-G1032.

10. Good M, et al. Breast milk protects against the development of necrotizing enterocolitis through inhibition of Toll-like receptor 4 in the intestinal epithelium via activation of the epidermal growth factor receptor. Mucosal Immunol. 2015;8(5):1166-1179.

11. Leaphart CL, et al. A critical role for TLR4 in the pathogenesis of necrotizing enterocolitis by modulating intestinal injury and repair. Immunol. 2007;179(7):4808-4820.

12. Agrawal V, Jaiswal MK, Ilievski V, Beaman KD, Jilling T, Hirsch E. Platelet-activating factor: a role in preterm delivery and an essential interaction with Toll-like receptor signaling in mice. Biol Reprod. 2014;91(5):119.

13. Soliman A, et al. Platelet-activating factor induces TLR4 expression in intestinal epithelial cells: implication for the pathogenesis of necrotizing enterocolitis. PLoS One. 2010;5(10):e15044.

14. Jilling $\mathrm{T}$, et al. The roles of bacteria and TLR4 in rat and murine models of necrotizing enterocolitis. JImmunol. 2006;177(5):3273-3282.

15. Wolfs TG, et al. Endotoxin induced chorioamnionitis prevents intestinal development during gestation in fetal sheep. PLoS One. 2009;4(6):e5837.

16. Neal MD, et al. Discovery and validation of a new class of small molecule Toll-like receptor 4 (TLR4) inhibitors. PLoS One. 2013;8(6):e65779.

17. Good M, et al. Amniotic fluid inhibits Toll-like receptor 4 signaling in the fetal and neonatal intestinal epithelium. Proc Natl Acad Sci U S A. 2012;109(28):11330-11335.

18. Su Y, Besner GE. Heparin-binding EGF-like growth factor (HB-EGF) promotes cell migration and adhesion via focal adhesion kinase. J Surg Res. 2014;189(2):222-231.

19. Ballance WA, Dahms BB, Shenker N, Kliegman RM. Pathology of neonatal necrotizing enterocolitis: a ten-year experience. J Pediatr. 1990;117(1 pt 2):S6-13.

20. Remon JI, et al. Depth of bacterial invasion in resected intestinal tissue predicts mortality in surgical necrotizing enterocolitis. JPerinatol. 2015;35(9):755-762

21. Iwasaki A, Medzhitov R. Control of adaptive immunity by the innate immune system. Nat Immunol. 2015;16(4):343-353.

22. Hepworth MR, et al. Immune tolerance. Science. 2015;348(6238):1031-1035.

23. von Burg N, et al. Activated group 3 innate lymphoid cells promote T-cell-mediated immune responses. Proc Natl Acad Sci U S A. 2014;111(35):12835-12840.

24. Mombaerts P, Iacomini J, Johnson RS, Herrup K, Tonegawa S, Papaioannou VE. RAG-1-deficient mice have no mature B and T lymphocytes. Cell. 1992;68(5):869-877.

25. Kunkel EJ, et al. Lymphocyte CC chemokine receptor 9 and epithelial thymus-expressed chemokine (TECK) expression distinguish the small intestinal immune compartment: epithelia expression of tissue-specific chemokines as an organizing principle in regional immunity. J Exp Med. 2000;192(5):761-768.

26. Papadakis KA, et al. The role of thymusexpressed chemokine and its receptor CCR9 on lymphocytes in the regional specialization of the mucosal immune system. JImmunol. 2000;165(9):5069-5076.

27. Lee AY, Eri R, Lyons AB, Grimm MC, Korner H. CC Chemokine Ligand 20 and its cognate receptor CCR6 in mucosal T cell immunology and inflammatory bowel disease: odd couple or axis of evil? Front Immunol. 2013;4:194.

28. Quaroni A, Isselbacher KJ, Ruoslahti E. Fibronectin synthesis by epithelial crypt cells of rat small intestine. Proc Natl Acad Sci U S A. 1978;75(11):5548-5552.

29. Ruemmele FM, et al. Lipopolysaccharide modulation of normal enterocyte turnover by toll-like receptors is mediated by endogenously produced tumour necrosis factor \{alpha\}. Gut. 2002;51(6):842-848.

30. Qureshi FG, et al. Increased expression and function of integrins in enterocytes by endotoxin impairs epithelial restitution. Gastroenterology. 2005;128(4):1012-1022.

31. Gribar SC, et al. Reciprocal expression and signaling of TLR4 and TLR9 in the pathogenesis and treatment of necrotizing enterocolitis. JImmunol. 2009;182(1):636-646.

32. Chaudhry A, et al. $\mathrm{CD} 4^{+}$regulatory T cells control TH17 responses in a Stat3-dependent manner Science. 2009;326(5955):986-991.

33. Mucida D, et al. Reciprocal TH17 and regulatory $T$ cell differentiation mediated by retinoic acid. Science. 2007;317(5835):256-260.

34. Lu P, et al. Animal models of gastrointestinal and liver diseases. Am J Physiol Gastrointest Liver Physiol. 2014;306(11):G917-G928.

35. Wolfs TG, et al. Localization of the lipopolysaccharide recognition complex in the human healthy and inflamed premature and adult gut. Inflamm Bowel Dis. 2010;16(1):68-75.

36. Nanthakumar NN, Fusunyan RD, Sanderson I, Walker WA. Inflammation in the developing human intestine: a possible pathophysiologic contribution to necrotizing enterocolitis. Proc Natl Acad Sci U S A. 2000;97(11):6043-6048.

37. Neal MD, et al. Toll-like receptor 4 is expressed on intestinal stem cells and regulates their proliferation and apoptosis via the p53 upregulated modulator of apoptosis. J Biol Chem. 2012;287(44):37296-37308.

38. Deshmukh HS, et al. The microbiota regulates neutrophil homeostasis and host resistance to Escherichia coli K1 sepsis in neonatal mice. Nat Med. 2014;20(5):524-530.

39. Verdier J, Ruemmele FM. Molecular mechanisms and cell targets of Th17 cells in the gastrointestinal tract: an innate sense of adaptivity. Int Rev Immunol. 2013;32(5-6):475-492.

40. Troncone E, Marafini I, Pallone F, Monteleone G Th17 cytokines in inflammatory bowel diseases: discerning the good from the bad. Int Rev Immunol. 2013;32(5-6):526-533. 
41. Zhang Z, Zheng M, Bindas J, Schwarzenberger P, Kolls JK. Critical role of IL-17 receptor signaling in acute TNBS-induced colitis. Inflamm Bowel Dis. 2006;12(5):382-388.

42. Yang J, Sundrud MS, Skepner J, Yamagata T. Targeting Th17 cells in autoimmune diseases. Trends Pharmacol Sci. 2014;35(10):493-500.

43. Goto Y, et al. Segmented filamentous bacteria antigens presented by intestinal dendritic cells drive mucosal Th17 cell differentiation. Immunity. 2014;40(4):594-607.

44. Goto Y, Ivanov II. Intestinal epithelial cells as mediators of the commensal-host immune crosstalk. Immunol Cell Biol. 2013;91(3):204-214.

45. Sano T, et al. An IL-23R/IL-22 circuit regulates epithelial serum amyloid A to promote local effector Th17 responses. Cell. 2015;163(2):381-393.

46. Wang C, Collins M, Kuchroo VK. Effector T cell differentiation: are master regulators of effector T cells still the masters? Curr Opin Immunol. 2015;37:6-10.

47. Reynolds JM, et al. Interleukin-17B antagonizes interleukin-25-mediated mucosal inflammation. Immunity. 2015;42(4):692-703.

48. Raverdeau M, Mills KH. Modulation of T cell and innate immune responses by retinoic acid. JImmunol. 2014;192(7):2953-2958.

49. Si J, Collins SJ. IL-3-induced enhancement of retinoic acid receptor activity is mediated through Stat5, which physically associates with retinoic acid receptors in an IL-3-dependent manner. Blood. 2002;100(13):4401-4409.

50. McElroy SJ, Weitkamp JH. Innate immunity in the small intestine of the preterm infant. Neoreviews. 2011;12(9):e517-e526.

51. Weitkamp JH, et al. Necrotising enterocolitis is characterised by disrupted immune regulation and diminished mucosal regulatory (FOXP3)/effector (CD4, CD8) T cell ratios. Gut. 2013;62(1):73-82.

52. Dingle BM, Liu Y, Fatheree NY, Min J, Rhoads JM, Tran DQ. FoxP3(+) regulatory T cells attenuate experimental necrotizing enterocolitis. PLoS One. 2013;8(12):e82963.
53. Sato T, et al. Single Lgr5 stem cells build cryptvillus structures in vitro without a mesenchymal niche. Nature. 2009;459(7244):262-265.

54. Shaffiey SA, et al. Intestinal stem cell growth and differentiation on a tubular scaffold with evaluation in small and large animals [published online ahead of print September 23, 2015]. Regen Med. doi:10.2217/rme.15.70.

55. Sodhi CP, et al. Intestinal epithelial TLR-4 activation is required for the development of acute lung injury after trauma/hemorrhagic shock via the release of HMGB1 from the gut. JImmunol. 2015;194(10):4931-4939.

56. Egan CE, Maurer KJ, Cohen SB, Mack M, Simpson KW, Denkers EY. Synergy between intraepithelial lymphocytes and lamina propria $\mathrm{T}$ cells drives intestinal inflammation during infection. Mucosal Immunol. 2011;4(6):658-670.

57. Neal MD, et al. A critical role for TLR4 induction of autophagy in the regulation of enterocyte migration and the pathogenesis of necrotizing enterocolitis. JImmunol. 2013;190(7):3541-3551. 